Check for updates

Cite this: RSC Adv., 2018, 8, 10489

Received 13th January 2018

Accepted 5th March 2018

DOI: $10.1039 / \mathrm{c} 8 \mathrm{ra00384j}$

rsc.li/rsc-advances

\section{Large-area perovskite solar cells - a review of recent progress and issues}

\author{
Yichuan Chen, (D) ab Linrui Zhang, ${ }^{a}$ Yongzhe Zhang, (D) *a Hongli Gao a and Hui Yan*a
}

In recent years, perovskite solar cells (PSCS) have attracted great attention in the photovoltaic research field, because of their high-efficiency (certified 22.1\%) and low-cost. In this review paper, we briefly introduce the history of efficiency development for PSCs, and discuss some of the major problems for large-area $\left(\geq 1 \mathrm{~cm}^{2}\right)$ PSC devices. In addition, we summarize the recent progress in the aspects of fabrication methods for largearea perovskite films, and improving the efficiency and stability of the large-area PSC devices. Finally, we give a short summary and outlook of large-area PSC devices. This article is mainly organized into three parts. The first part focuses on the main fabricating technologies for large-area perovskite films. The second section discusses some methods that are used to improve the efficiency of PSCs. In the last part, different approaches are used to improve the stability of PSCs.

\section{Introduction}

Due to the growing population, the global energy demand is increasing year by year. Moreover, the global energy demand is predicted to double by 2050.,2 Thus, the development of renewable energy becomes an imminent requirement, such as water energy, wind energy, and solar energy. The photovoltaic power generation capacity is installed to be $303 \mathrm{GW}$ and increased $75 \mathrm{GW}$ in 2016. In 2016, photovoltaic power generation accounted for only $1.5 \%$ of the world's total electricity generation. So high performance, long-term stability, low cost and environmental friendly solar cells become the focus of current energy research.

PSCs have attracted great attention in photovoltaic research in recent years, because of their high-efficiency (certified $22.1 \%)^{3}$ and low-cost. Meanwhile, organic-inorganic perovskites have a high optical absorption coefficient ${ }^{4}$ and the diffusion lengths exceed $1 \mu \mathrm{m}$ for electrons and holes. ${ }^{5}$ So, organic-inorganic perovskite is an ideal absorber material for solar cells, ${ }^{6-19}$ photodetectors, ${ }^{20-22}$ light-emitting diodes, ${ }^{23-26}$ etc.

In recent years, hybrid metal halide perovskite materials have revolutionized the field of photovoltaics materials research, due to the power conversion efficiency (PCE) of PSC devices having been rapidly improved, from the point $3.8 \%$ in $2009,{ }^{6}$ up to $22.6 \%$ in 2017 (ref. 3) (certified $22.1 \%$ ). ${ }^{3}$ It attracted attention of researchers working on various photovoltaic technologies, especially dye solar cells (DSCs) and organic photovoltaic (OPV) with emphasis on better efficiency. In 2009, T.

${ }^{a}$ College of Materials Science and Engineering, Beijing University of Technology, Beijing, 100124, China. E-mail: yzzhang@bjut.edu.cn; hyan@bjut.edu.cn

${ }^{b}$ School of Mechanical and Electrical Engineering, Jingdezhen Ceramic Institute, Jingdezhen, Jiangxi 333403, China
Miyasaka et al. ${ }^{6}$ has creatively made $\mathrm{CH}_{3} \mathrm{NH}_{3} \mathrm{PbBr}_{3} / \mathrm{TiO}_{2}$-based and $\mathrm{CH}_{3} \mathrm{NH}_{3} \mathrm{PbI}_{3} / \mathrm{TiO}_{2}$-based DSCs, the PCE of the cells is $3.13 \%$ and $3.81 \%$, respectively. The PSCs attracted researchers' attention then happened in 2012, when M. Grätzel and N. G. Park et al. ${ }^{27}$ made PSCs device using perovskite films as the photoactive absorber layer, the $\mathrm{mp}-\mathrm{TiO}_{2}$ and spiro-MeOTAD were used as the electron transport layer (ETL) and hole transport layer (HTL), respectively (Fig. 1), achieving the PCE of 9.7\%. In 2013, M. Z. Liu, M. B. Johnston and H. J. Snaith ${ }^{8}$ fabricated planar heterojunction PSCs via vapor deposition, and the efficiency of the PSCs device is up to $15.4 \%$. The yttrium (Y) doping the $\mathrm{TiO}_{2}$ (ETL) improves the electron transport channel in the PSCs device, and increase its carrier concentration and modify the ITO electrode to reduce its work function. These changes achieved a PCE of $19.3 \%{ }^{28}$ In 2015 , S. I. Seok et al..$^{29}$ attained an efficiency of PSCs up to $20.1 \%$. In 2016, A. Zettl et al. ${ }^{30}$ made an architecture of $\mathrm{GaN} / \mathrm{CH}_{3} \mathrm{NH}_{3} \mathrm{SnI}_{3} /$ monolayer $\mathrm{h}-\mathrm{BN} / \mathrm{CH}_{3} \mathrm{NH}_{3}$ $\mathrm{PbI}_{3-x} \mathrm{Br}_{x} / \mathrm{HTL}$ and graphene aerogel/Au (Fig. 2). The graded bandgap PSCs demonstrated with PCE averaging 18.4\%, with a best of $21.7 \%$. Other researchers, E. H. Sargent et al. ${ }^{31}$ (2017) achieved the certified efficiencies of $20.1 \%$ via contactpassivation strategy, retaining $90 \%$ (97\% after dark recovery) of their initial PCE after 500 hours of continuous roomtemperature. Meanwhile, E. K. Kim, J. H. Noh, and S. I. Seok et al. ${ }^{3}$ reported that the introduction of additional iodide ions into the organic cation solution, that was used to form the perovskite layers through an intramolecular exchanging process and decrease the concentration of deep-level defects. The certified PCE of PSCs attained $22.1 \%{ }^{3}$

In addition, high efficiency PSCs devices include not only small devices, but also larger cells. A PSCs device with area of large-area $\left(\geq 1 \mathrm{~cm}^{2}\right)$ and maximum PCE of $20.5 \%$ (certified 
(a)

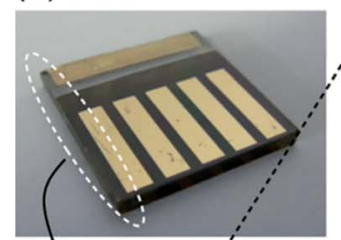

(b)

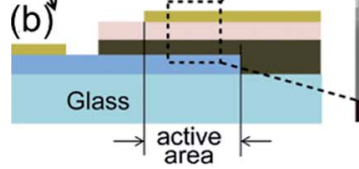

(c)

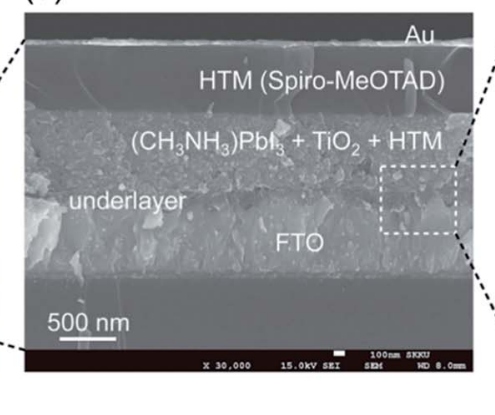

(d)

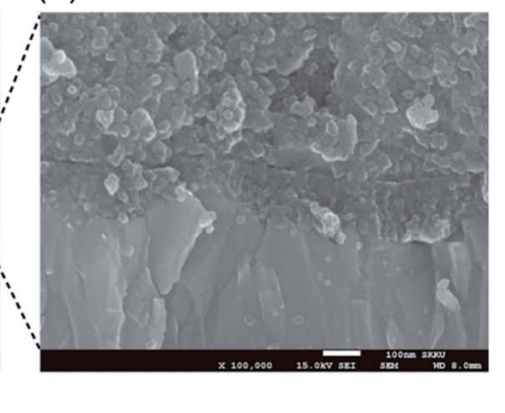

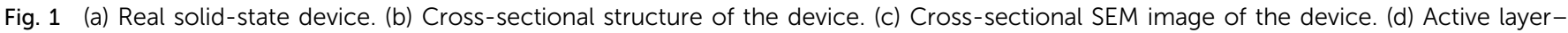
underlayer-FTO interfacial junction structure. ${ }^{27}$
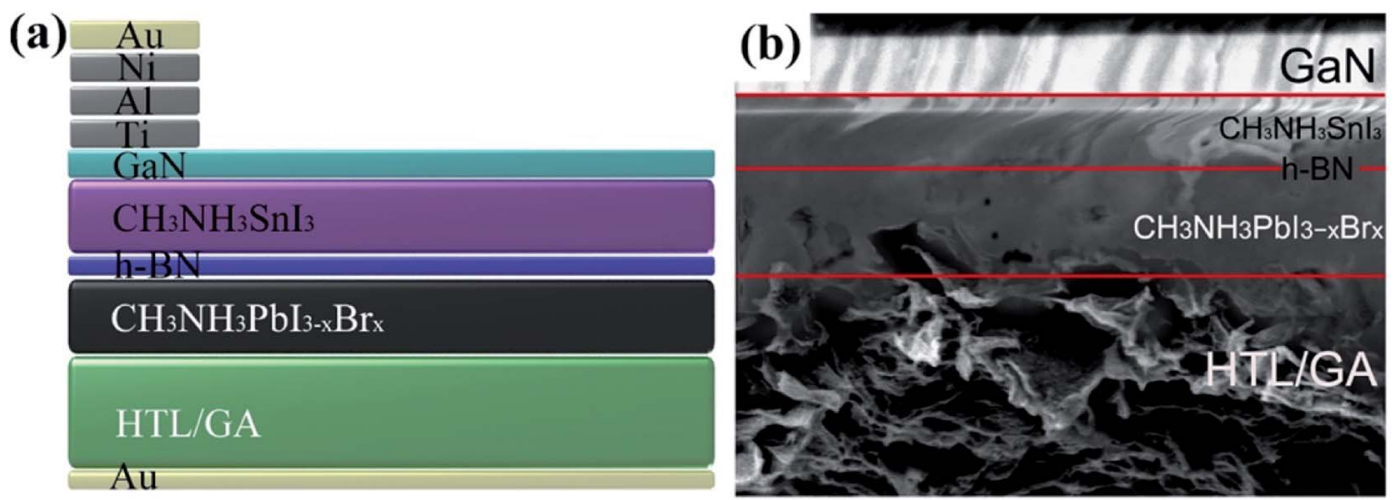

Fig. 2 (a) Cross-sectional schematic. (b) SEM images of perovskite cell with integral monolayer h-BN and graphene aerogel. ${ }^{30}$

19.7\%) has been reported. ${ }^{3}$ Table 1 shows some results for largearea PSCs have been reported in the literatures.

But, for large-area PSCs device, it still has some issues need to be solved, namely fabrication, stability, hysteresis, fabrication cost and environmental concerns. Such as, the continuous fabrication of cracks-free and pinholes-free the perovskite and the selective carrier extraction layers films is difficulty with large-area PSCs devices. The dilemma with optimizing such charge carrier extraction layers in solar cells is that the film should be thin to minimize resistive losses, while at the same time, it should cover the entire collector area in a contiguous and uniform manner. ${ }^{48}$ In the large-area PSCs device, surfaces, bulk defects and interfaces introduce recombination centers that lead to fast nonradiative losses, ${ }^{\mathbf{4 9}}$ and interface losses, which lead to the $V_{\mathrm{oc}}, J_{\mathrm{sc}}$ and fill factor (FF) decrease. Meanwhile, the perovskite material is easily thermal decomposition and hydrodecomposition, that leads to the lack of stability for PSCs device. The poor stability of the perovskite materials and devices is a big challenge, which hinder the PSCs device could be transferred from the laboratory to industry and outdoor applications. Thus, for large-area PSCs device, the major challenges relate to the improving efficiency and keeping the stability of the device. In this review paper, giving an update of the PSCs field, briefly, introducing the history of PSCs and then focus on the key progress of the fabrication, improving the efficiency and the stability of the large-area PSCs device.

\section{Perovskite structure and typical PSCs structure}

\subsection{Perovskite structure and characteristics}

Perovskite was discovered in 1839, which originally referred to a kind of ceramic oxides with the general molecular formula $\mathrm{ABX}_{3} .{ }^{1}$ Recently, PSCs absorber layer is mainly organic-inorganic perovskite layer, the general molecular formula is also $\mathrm{ABX}_{3}$ (Fig. 3), where $\mathrm{A}$ is an organic cation (i.e. $\mathrm{CH}_{3} \mathrm{NH}_{3}{ }^{+}$, $\mathrm{NH}_{2} \mathrm{CH}=\mathrm{NH}_{2}{ }^{+}, \mathrm{CH}_{3} \mathrm{CH}_{2} \mathrm{NH}_{3}{ }^{+}$), $\mathrm{B}$ is metal cation (i.e. $\mathrm{Pb}^{2+}, \mathrm{Sn}^{2+}$, $\mathrm{Ge}^{2+}$ ) and $\mathrm{X}$ is halogen anion (i.e. $\mathrm{F}^{-}, \mathrm{Cl}^{-}, \mathrm{Br}^{-}, \mathrm{I}^{-}$), are the most relevant ones for PSCs.

The perovskite arrangement is approximated on its geometric tolerance factor $(t)$,

$$
t=\frac{r_{\mathrm{A}}+r_{\mathrm{X}}}{\sqrt{2}\left(r_{\mathrm{B}}+r_{\mathrm{X}}\right)}
$$

where $r_{\mathrm{A}}, r_{\mathrm{B}}$ and $r_{\mathrm{X}}$ are the efficient ionic radius for $\mathrm{A}, \mathrm{B}$ and $\mathrm{X}$ ions, respectively. When the $t=1.0$, the perovskite is a perfect cubic perovskite. ${ }^{50}$ However, octahedral distortion is assessed when $t<1$, which influences electronic characteristics. ${ }^{51}$ For alkali metal halide perovskite, formability is anticipated for $0.813<t<1.107 .{ }^{50,51}$ In Table 2, the $r_{\mathrm{A}}$ in $\mathrm{APbX}_{3}(\mathrm{X}=\mathrm{Cl}, \mathrm{Br}, \mathrm{I})$ perovskite has been calculated for $t=0.8$ and $t=1$ based on effective ionic radii. ${ }^{51}$ As the tolerance of $\mathrm{CH}_{3} \mathrm{NH}_{3} \mathrm{PbI}_{3}\left(\mathrm{MAPbI}_{3}\right)$ 
Table 1 Summary of large-area perovskite solar cells

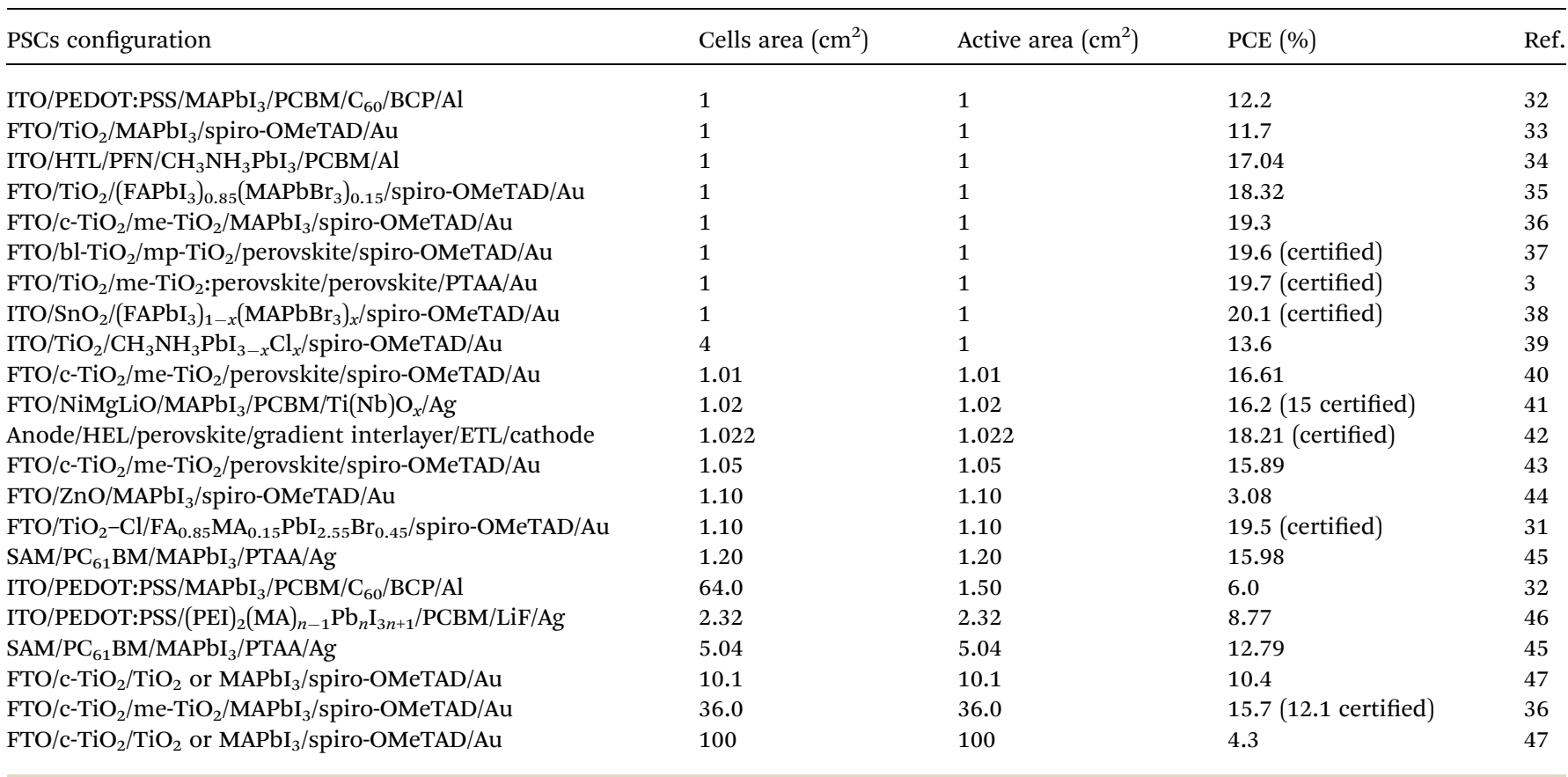
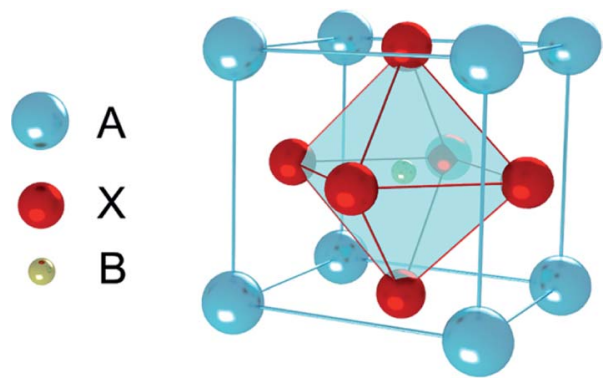

Fig. $3 \quad \mathrm{ABX}_{3}$ perovskite structure.

Table 2 Estimation of $\mathrm{A}$ cation radii in $\mathrm{APbX}_{3}$

\begin{tabular}{llll}
\hline$r_{\mathrm{Pb}}{ }^{a}$ & $\mathrm{X}^{a}$ & $r_{\mathrm{A}}{ }^{b}$ for $t=0.8$ & $r_{\mathrm{A}}{ }^{b}$ for $t=1.0$ \\
\hline $\mathrm{Pb}^{2+}(1.19 \AA)$ & $\mathrm{Cl}^{-}\left(r_{\mathrm{Cl}}=1.81 \AA\right)$ & $1.58 \AA$ & $2.43 \AA$ \\
& $\mathrm{Br}^{-}\left(r_{\mathrm{Br}}=1.96 \AA\right)$ & $1.60 \AA$ & $2.50 \AA$ \\
& $\mathrm{I}^{-}\left(r_{\mathrm{I}}=2.20 \AA\right)$ & $1.64 \AA$ & $2.59 \AA$
\end{tabular}

${ }^{a}$ Effective ionic radii for coordination number of 6 .

${ }^{b} r_{\mathrm{A}}=t \times \sqrt{2}\left(r_{\mathrm{B}}+r_{\mathrm{X}}\right)-r_{\mathrm{X}} \cdot{ }^{50,51}$

is 0.83 , in this manner, the deviation from a perfect cubic structure is likely to happen. ${ }^{50,51}$

In the visible range, for the $\mathrm{MAPbI}_{3}$, the effective absorption coefficient is around $1.0 \times 10^{5}\left(\mathrm{~mol} \mathrm{~L}^{-1}\right)^{-1} \mathrm{~cm}^{-1}$ at $550 \mathrm{~nm},{ }^{4,52}$ when the thickness of perovskite films range is $500-600 \mathrm{~nm}$, it can absorb complete light in films. Meanwhile, organic-inorganic perovskite exhibits better charge transfer characteristics. $\mathrm{H}$. J. Snaith et al. ${ }^{5}$ reported the diffusion lengths $\left(L_{\mathrm{D}}\right)$ of the electrons and holes in $\mathrm{MAPbI}_{3}$ and $\mathrm{MAPbI}_{3-x} \mathrm{Cl}_{x}$, the $L_{\mathrm{D}}$ of $\mathrm{MAPbI}_{3}$ is $130 \mathrm{~nm}$ (electrons) and $100 \mathrm{~nm}$ (holes) and this of $\mathrm{MAPbI}_{3-x} \mathrm{Cl}_{x}$ is
$1100 \mathrm{~nm}$ (electrons) and $1200 \mathrm{~nm}$ (holes), respectively. ${ }^{5}$ So, the organic-inorganic perovskite is an ideal absorber layer material for solar cells.

\subsection{Typical PSCs structure}

Some of the typical structures of PSCs are shown in Fig. 4. The typical PSCs structures include the mesoporous structure (Fig. 4(a)), the planar heterojunction structure (Fig. 4(b)) and the inverted planar heterojunction structure (Fig. 4(c)). PSCs with regular configuration is transparent conductive oxide (TCO)/blocking layer (electron transport layer (ETL))/perovskite absorber layer/hole transport layer (HTL) material/gold (Au). The widely accepted a simplified operation principle of PSCs is presented as: perovskite absorber layer absorbs light and generates charges while the light on the PSCs. The electrons and holes pairs are created by the thermal energy, which diffuse and get separate through electron and hole selective contacts, respectively (Fig. $4(\mathrm{~d}))^{53}$ Once electrons and holes are present at the cathode and anode, respectively, external load can be powered by connecting a circuit through it.

$\mathrm{TiO}_{2}$ is the most common ETL material, $, 3,6,7,54$ meanwhile, other ETL materials have been used to attain over $10 \%$ efficiencies (e.g. $\mathrm{ZnO},{ }^{13,55,56} \mathrm{SnO}_{2},{ }^{57-59} \mathrm{PCBM}^{60-65}$ LBSO, ${ }^{66}$ etc.). Spiro-OMeTAD is the widely used HTL material, ${ }^{3,57,67}$ the certified PCE of $22.1 \%$ in small cells. ${ }^{3}$ Meanwhile, other HTL materials have been used to achieve over 10\% efficiencies (e.g. PTAA, ${ }^{29,66,68}$ P3HT, ${ }^{69-71}$ PEDOT:PSS, ${ }^{60,61,72}$ CuSCN ${ }^{73,74}$ triazine-Th-OMeTPA, ${ }^{75}$ PVCz-OMeDAD,${ }^{76}$ OMeTPABDT, ${ }^{77} \mathrm{NiO}_{x},{ }^{56,64,78,79} \mathrm{CuGaO}_{2},{ }^{54} \mathrm{X} 26,{ }^{80} \mathrm{X} 36,{ }^{80} \mathrm{NiMgLiO}^{41}$ etc.). Carbon materials, ${ }^{81-85}$ aluminum, ${ }^{34,56,61,62}$ silver, ${ }^{64,65,86}$ and gold ${ }^{87-90}$ have been used as electrode. ${ }^{53}$ Fig. 5 shows the energy levels for some commonly used ETL materials, HTL materials and absorbers materials. 
(a)

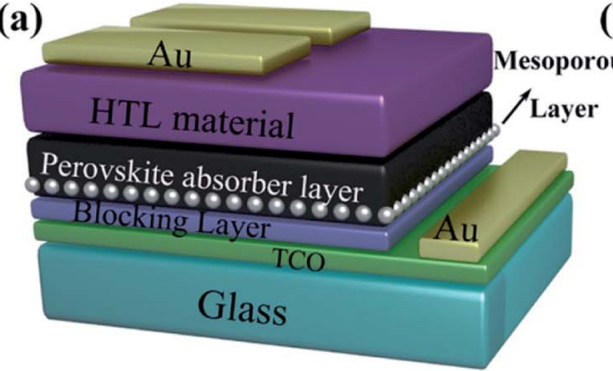

(c)

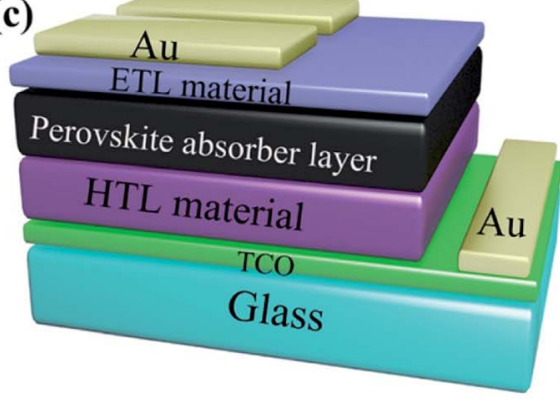

(b)

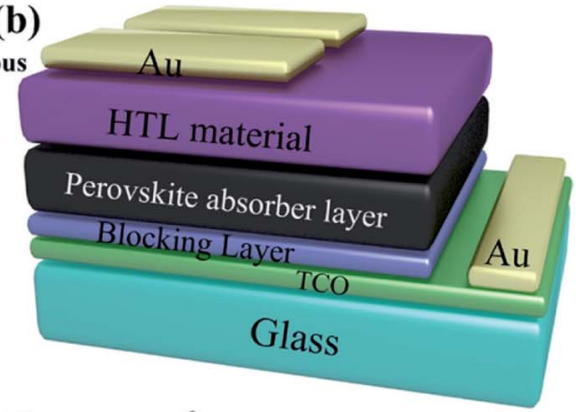

(d)

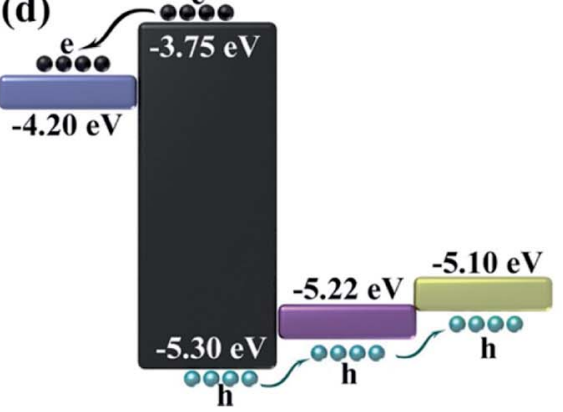

Fig. 4 Different structural configurations of PSCs, (a) mesoporous structure, (b) planar heterojunction structure, (c) inverted planar heterojunction structure and (d) schematic of electron and hole transportation.

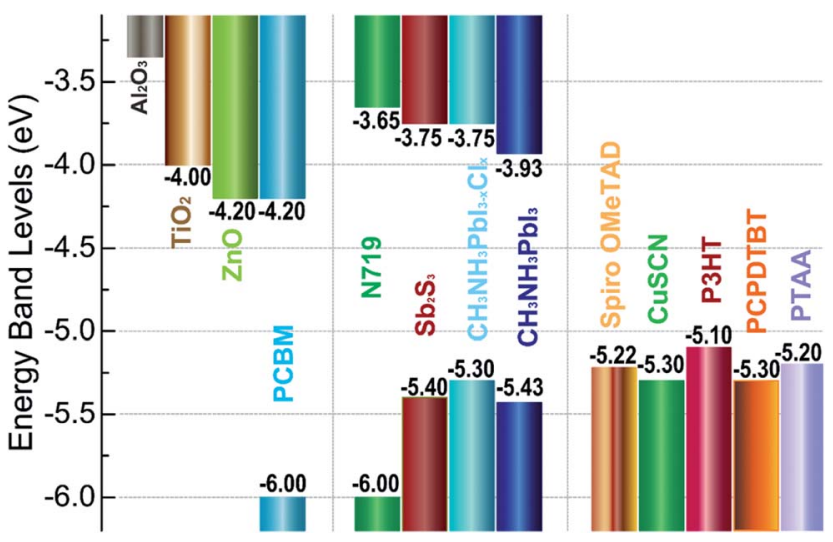

Fig. 5 Energy levels for some materials of ETL (left), absorbers (middle) and HTL (right) in solar cells.

\section{Large-area $\left(\geq 1 \mathrm{~cm}^{2}\right)$ perovskite films fabricating technologies}

The continuous fabrication of cracks- and pinholes-free the perovskite films and the selective carrier extraction layers films is difficulty for the large-area PSCs devices. So, some researchers have reported many fabrication methods to improve the quality of the large-area perovskite films.

\subsection{Spin-coating and vacuum flash-assisted solution process (VASP)}

Spin-coating has been widely used to fabricate the large-area perovskite films. ${ }^{16,35,39-41,45,91}$ The main advantage of the spincoating method is to deposit thin films with well-defined the composition of chemical elements and the film thicknesses. Spin-coating includes one step spin-coating and two step spin-
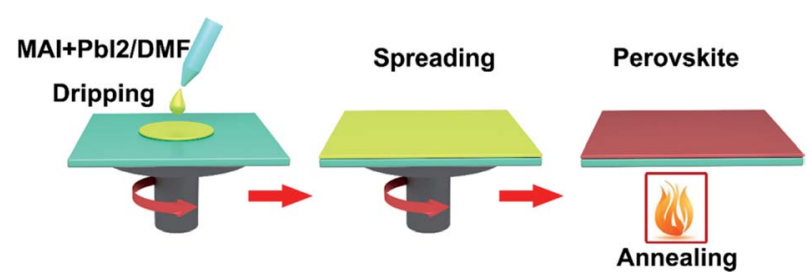

Fig. 6 One-step deposited perovskite films.

coating. One step spin-coating, briefly, methyl ammonium iodide (MAI) and lead iodide $\left(\mathrm{PbI}_{2}\right)$ powders are mixed and dissolved in $N, N$-dimethylformamide (DMF) or dimethyl sulfoxide (DMSO), the mixed solution is spun on a TCO substrate and then annealed, attaining the perovskite films (Fig. 6). In 2015, M. Grätzel and L. Y. Han et al. ${ }^{41}$ prepared perovskite absorber films via one step spin-coating, they achieved largearea PSCs with an active area $1.02 \mathrm{~cm}^{2}$ that had a PCE $>15 \%$ (certified 15\%). In 2016, W. Qiu and P. Heremans et al. ${ }^{39}$ achieved large-area PSCs with $4 \mathrm{~cm}^{2}$ aperture area and an active area of $1 \mathrm{~cm}^{2}$, that had a PCE of $13.6 \%$.

Aiming at uncovered pinhole areas derive from large perovskite grains, M. J. Kim and G. H. Kim et al. ${ }^{35}$ also developed one step spin-coating, and using high-temperature short-time annealing (HTSA) process (Fig. 7(a)), achieving the perovskite grains with sizes more than $1 \mu \mathrm{m}$ without pinhole (Fig. $7(\mathrm{~d}, \mathrm{e}, \mathrm{h}$, i)). In addition, the VASP was used to fabricate perovskite film (Fig. 8(a)), the sizes of perovskite grains were between 400 and $1000 \mathrm{~nm}$ (Fig. 8(c)), which covered the $\mathrm{TiO}_{2}$ layer. ${ }^{37}$

Two-step spin coating, briefly, MAI and $\mathrm{PbI}_{2}$ powders are dissolved in DMF or DMSO, respectively. ${ }^{16}$ First, the $\mathrm{PbI}_{2}$ solution is spun coating on a TCO substrate and then annealing, 
achieving the $\mathrm{PbI}_{2}$ films. Second, the MAI solution is spun coating on $\mathrm{PbI}_{2}$ films and then annealing, achieving the perovskite films (Fig. 9). In 2016, C. Chang et al. ${ }^{45}$ prepared perovskite absorber films with two step spin-coating, they achieved large-area PSCs with an active area $1.2 \mathrm{~cm}^{2}$ that had a PCE of 16.2\%. In 2017, E. K. Kim, J. H. Noh and S. I. Seok et al. ${ }^{3}$ achieved large-area PSCs with an active area $1 \mathrm{~cm}^{2}$ that had a certified PCE of $19.7 \%$. In 2017, X. W. Zhang and J. B. You et $a l .{ }^{38}$ have adopted two-step spin-coating method to fabricate the $\left(\mathrm{FAPbI}_{3}\right)_{1-x}\left(\mathrm{MAPbBr}_{3}\right)_{x}$ films and configure $\mathrm{n}-\mathrm{i}-\mathrm{p}$ planar structure PSCs with an active area $1 \mathrm{~cm}^{2}$ that has a PCE of $20.1 \%$.

\subsection{Vapor deposition}

Comparing to the fabrication of the PSCs device with the spincoating technology, vapor deposition technology offers a very superior device and superior performance (Fig. 10(a)). The vapor deposition includes dual-source evaporation technology, ${ }^{8}$ vapor-solid reaction, ${ }^{32}$ and vapor-assisted method, ${ }^{50}$ etc. For dual-source co-evaporation technology, it is that $\mathrm{PbI}_{2}$ powders and MAI powders are made as target source, and pre-heated to $116{ }^{\circ} \mathrm{C}$ and $325^{\circ} \mathrm{C}$, respectively, which has achieved the PSCs yield an PCE of $15.4 \% .^{8}$ This method fabricates high quality and uniformity of the perovskite films, subsequently resulting in good performance. But this method is very dependent on high

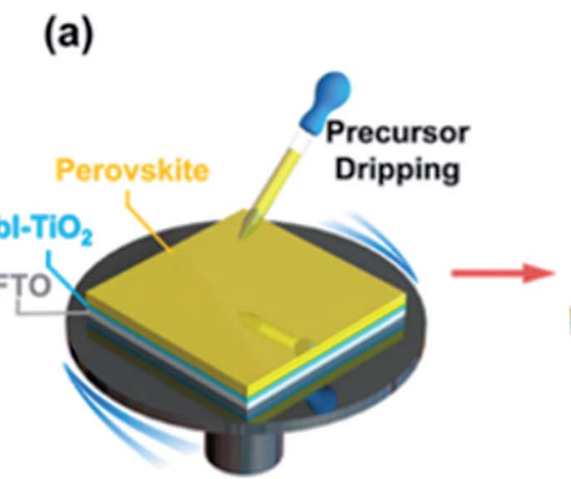

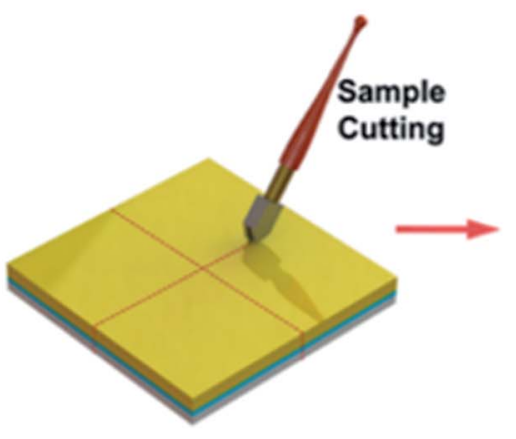

As-deposition Film

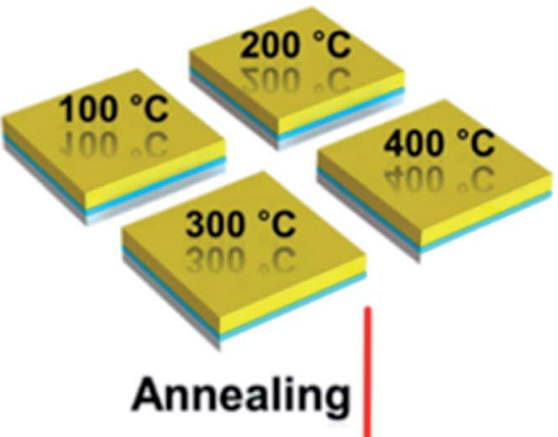

Annealing

Spin Coating

$200^{\circ} \mathrm{C}$ for $2 \mathrm{~min}$
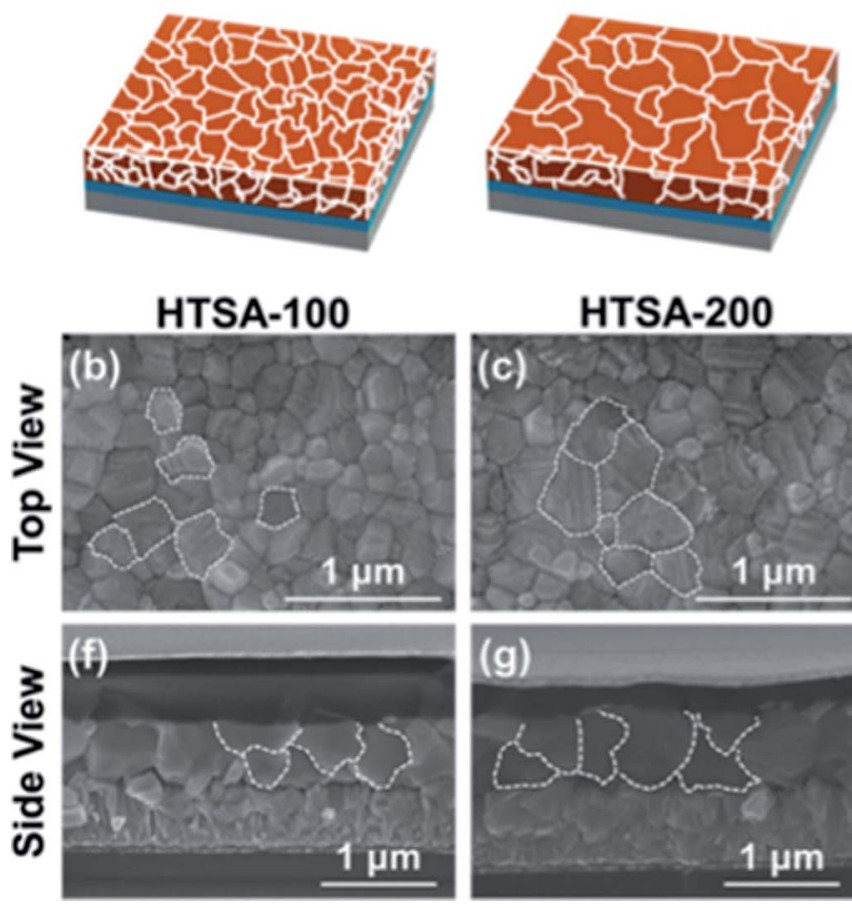

HTSA-200
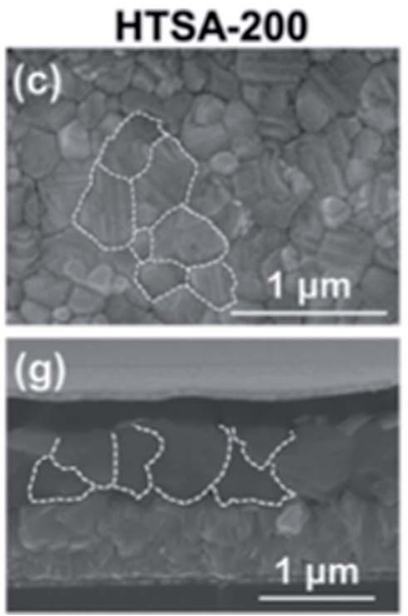

$300{ }^{\circ} \mathrm{C}$ for $8 \mathrm{sec}$

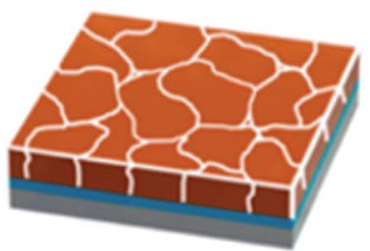

HTSA-300
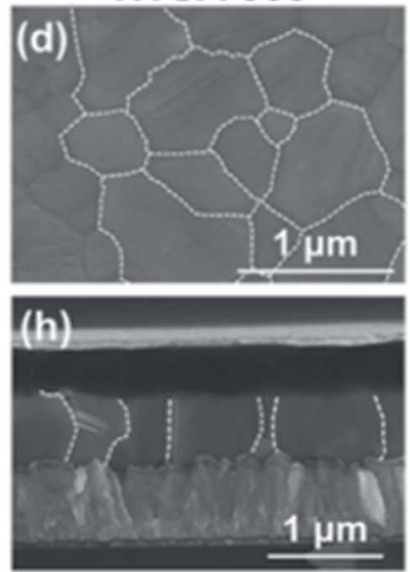

$400{ }^{\circ} \mathrm{C}$ for $4 \mathrm{sec}$
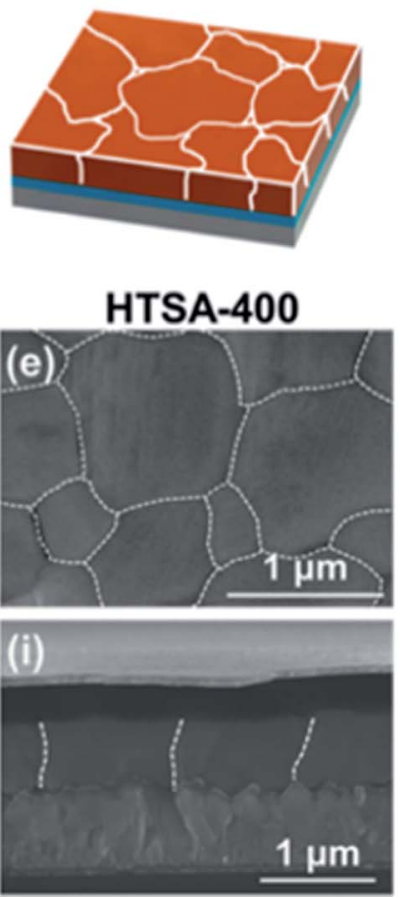

Fig. 7 (a) Schematic illustration of the annealing processes. (b-e) Surface SEM images (top view) of the perovskite films. (f-i) Their crosssectional images (side view), respectively. ${ }^{35}$ 


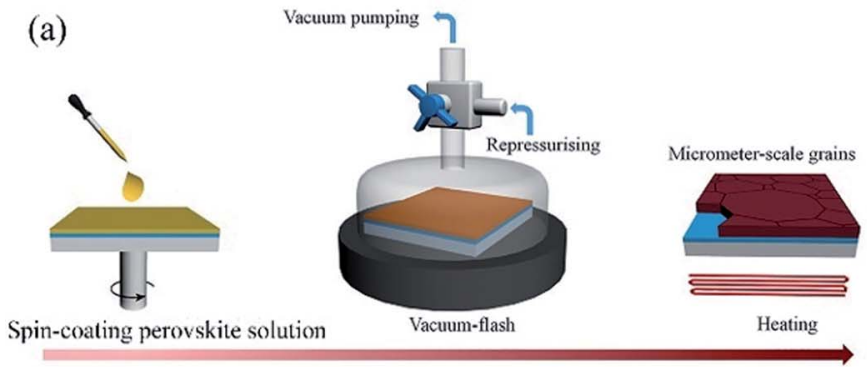

(c)

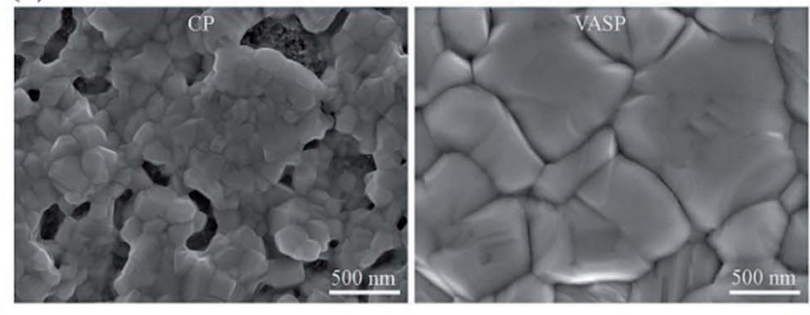

(b)

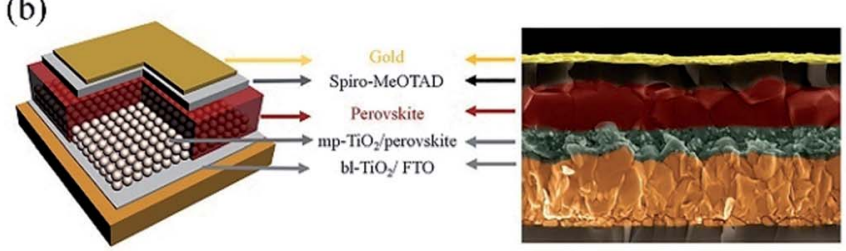

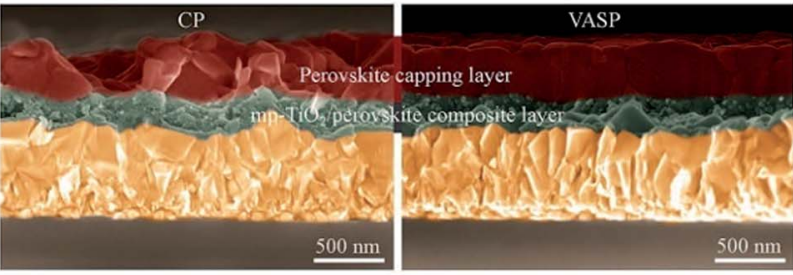

Fig. 8 (a) Schematic illustration of nucleation and crystallization procedures during the formation of perovskite film via VASP. (b) Schematic illustration of the PSCS configuration and SEM image. (c) Surface and cross-sectional SEM images of the perovskite films fabricated by the conventional process (CP) and VASP. ${ }^{37}$

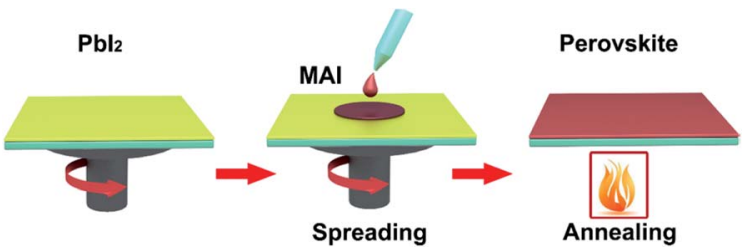

Fig. 9 Two-step deposited perovskite films.

temperature and high vacuum conditions. Alternate methods research in the literature ${ }^{32}$ is vapor-solid reaction (VSR), depositing the perovskite film with low temperature (Fig. 10(b)). First, the $\mathrm{PbI}_{2}$ film was spin-coated onto the ETL, and then baking on a $70{ }^{\circ} \mathrm{C}$ hot plate in air for $10 \mathrm{~min}$. Second, MAI powders were dissolved in ethanol. Then the solution was homogeneously sprayed onto the bottom surface of the top plate that had been keeping at $80{ }^{\circ} \mathrm{C}$. Finally, inside vacuum desiccator, two parallel hot plates (PHP) were putted together to synthesize perovskite thin films. ${ }^{32} \mathrm{H}$. Zhou and S. Yin et al. ${ }^{32}$ used this method to achieve the $8 \times 8 \mathrm{~cm}^{2}$ PSCs module, the average PCE was $6.0 \%$ with the active area of $1.5 \mathrm{~cm}^{2}$.

\subsection{Gas-induced method}

For the organic-inorganic halide perovskites (OIHPs) materials, gas-induce formation/transformation (GIFT) reveal surprising properties, such as gas-induced phase/morphology transformation. ${ }^{92}$ Z. Zhou, S. Pang, G. Cui et al.$^{93}$ reported that the discovery of $\mathrm{CH}_{3} \mathrm{NH}_{2}$ (MA) induced phase/morphology transformation of the $\mathrm{MAPbI}_{3}$. As show in Fig. 11, MA gas is introduced at room temperature (RT), after $120 \mathrm{~min}$, two $\mathrm{MAPbI}_{3}$ single-crystals become liquefied ( $\left.\mathrm{MAPbI}_{3} \cdot x \mathrm{CH}_{3} \mathrm{NH}_{2}\right)$, eventually, merge into one liquid sphere. ${ }^{93}$ Then MA gas is removed, after 120 min, perovskite back-conversion completed. Fig. 12(b) shows a poor quality of $\mathrm{MAPbI}_{3}$ thin film (incomplete coverage, rough), then the MA gas treatment has been introduced to create smooth, uniform and full coverage $\mathrm{MAPbI}_{3}$ thin films (Fig. 12(c)). ${ }^{93}$

In 2017, M. Grätzel and L. Han et al. ${ }^{36}$ achieved $8 \times 8 \mathrm{~cm}^{2}$ perovskite films via GIFT, briefly, at atmospheric environment, dried $\mathrm{CH}_{3} \mathrm{NH}_{2}$ gas $\left(0.5 \mathrm{l} \mathrm{min}^{-1}\right)$ was passed into a bottle that contained $2 \mathrm{mmol} \mathrm{CH}_{3} \mathrm{NH}_{3} \mathrm{I}$ or $\mathrm{PbI}_{2}$ powders (Fig. 13). After $30 \mathrm{~min}$, the $\mathrm{CH}_{3} \mathrm{NH}_{3} \mathrm{I}$ powders changed into transparent colorless liquid $\left(\mathrm{CH}_{3} \mathrm{NH}_{2} \mathrm{I} \cdot 3 \mathrm{CH}_{3} \mathrm{NH}_{2}\right)$, and the $\mathrm{PbI}_{2}$ powders

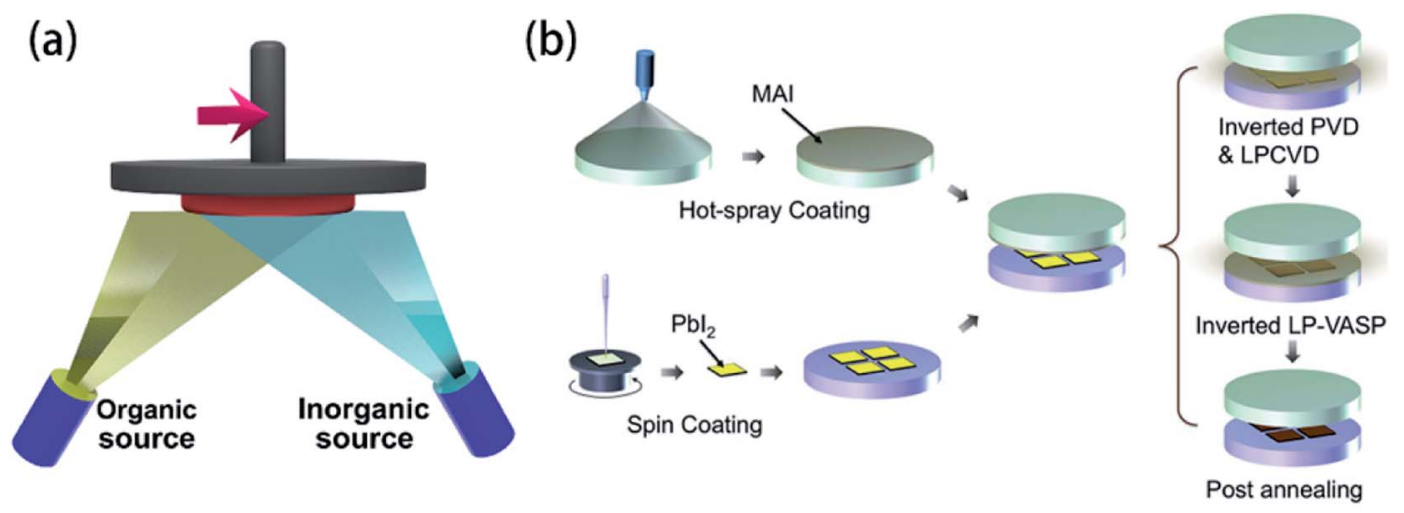

Fig. 10 (a) Schematic illustration of double source co-evaporation. (b) Schematic of vapor-solid reaction method. ${ }^{32}$ 


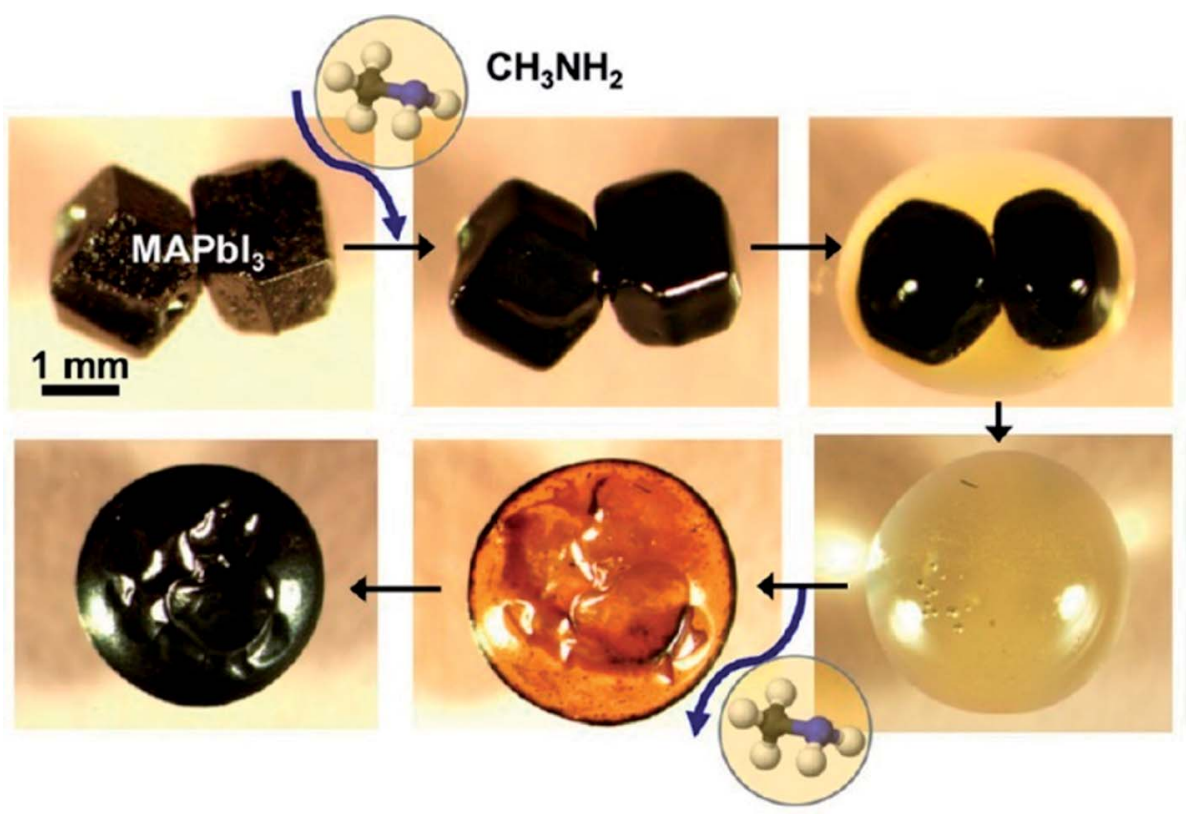

Fig. 11 In situ optical microscopy of the morphology evolution of two touching MAPb/ 3 perovskite crystals (same magnification) upon exposure to $\mathrm{CH}_{3} \mathrm{NH}_{2}$ gas and $\mathrm{CH}_{3} \mathrm{NH}_{2}$ degassing. ${ }^{93}$

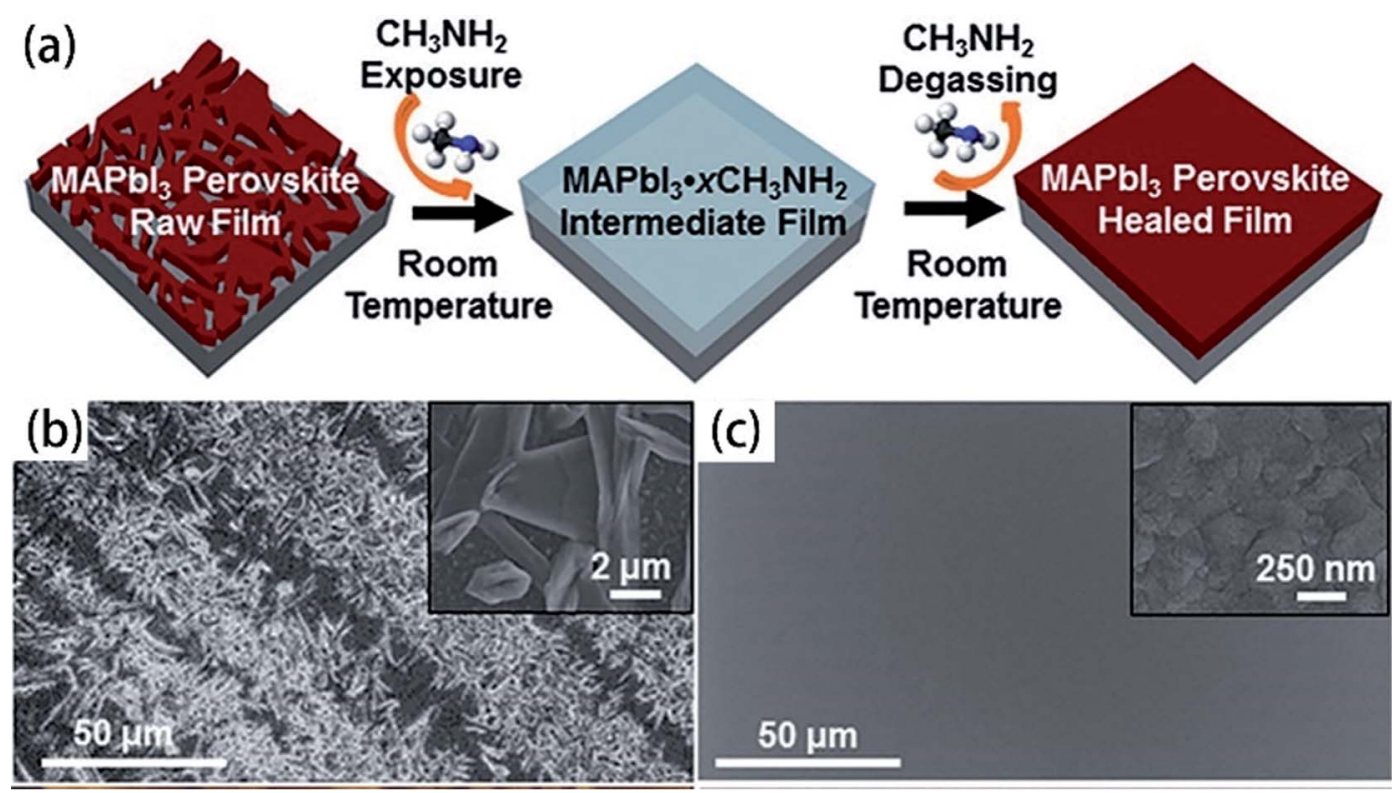

Fig. 12 (a) Schematic illustration of MA induced defect-healing of MAPbI 3 perovskite thin films. SEM images of MAPbI 3 thin films: (b) raw film and (c) healed film. ${ }^{93}$

changed into a pale-yellow paste $\left(\mathrm{PbI}_{2} \cdot \mathrm{CH}_{3} \mathrm{NH}_{2}\right.$, Fig. 13). ${ }^{36}$ For the synthesis of perovskite precursor, $\mathrm{CH}_{3} \mathrm{NH}_{2} \mathrm{I} \cdot 3 \mathrm{CH}_{3} \mathrm{NH}_{2}$ and $\mathrm{PbI}_{2} \cdot \mathrm{CH}_{3} \mathrm{NH}_{2}$ were blended stoichiometrically and ultrasonicated for $15 \mathrm{~min}$ (Fig. 13). ${ }^{36}$ The perovskite precursor (200 $\mu \mathrm{l})$ was dropped on a $8 \times 8 \mathrm{~cm}^{2}$ substrate and then the precursor was covered by the polyimide (PI) film. ${ }^{36}$ A pressure of 120 bar was loaded via a pneumatically driven squeezing board which spread the liquid precursor under the PI film. The pressure was held for $60 \mathrm{~s}$ and then unloaded. The thin liquid film covered with the PI film was heated at $50{ }^{\circ} \mathrm{C}$ for $2 \mathrm{~min}$ before peeling off the PI film. After peeling the PI film $\left(50 \mathrm{~mm} \mathrm{~s}^{-1}\right)$, a dense and uniform perovskite film was formed (Fig. 14(b)). ${ }^{36}$ They achieved the PSCs with the device area $36 \mathrm{~cm}^{2}$ (Fig. 14(c)) that had a certified PCE of $12.1 \% .^{36}$

\subsection{Other approaches}

In addition, a blade coating technology is also frequently used, the schematic shows in Fig. 15. ${ }^{22}$ The advantage of the blade 


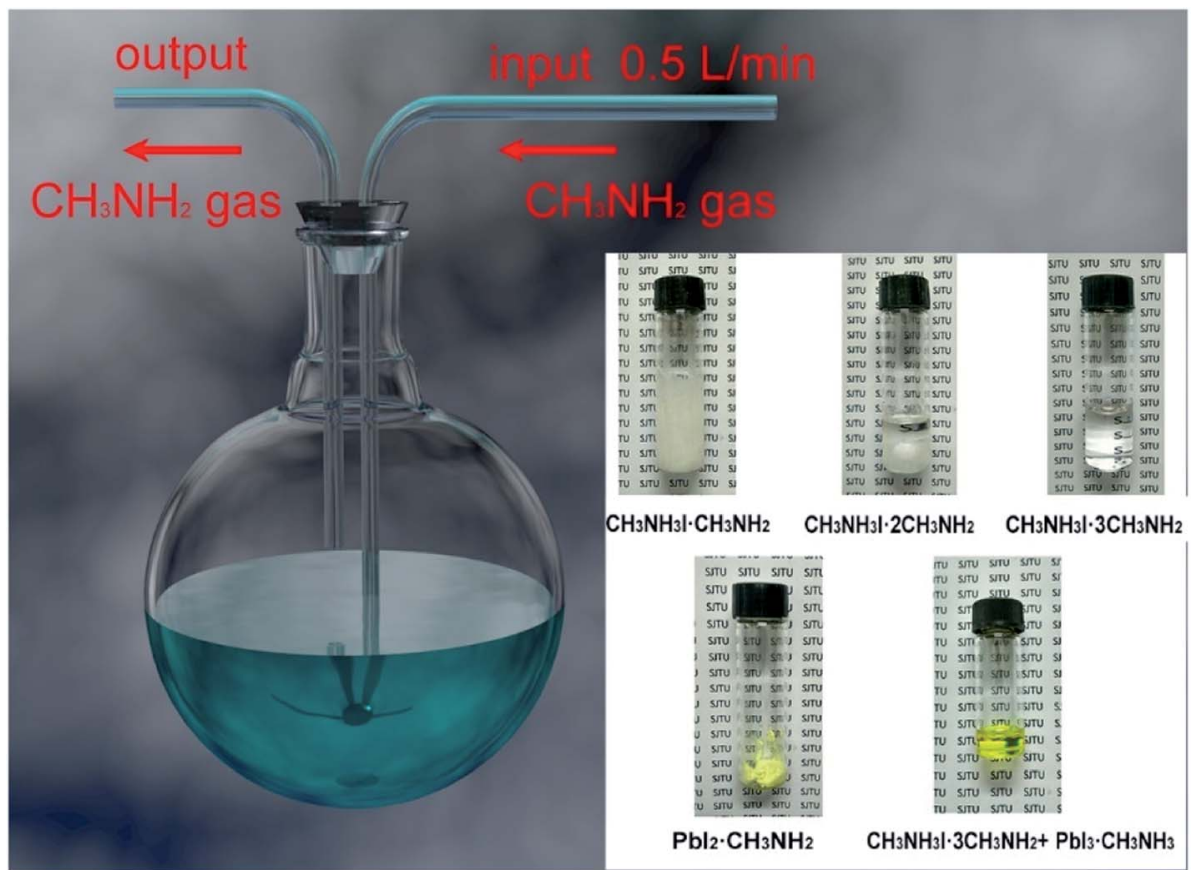

Fig. 13 Diagram of the $\mathrm{CH}_{3} \mathrm{NH}_{2}$ introduced $\mathrm{CH}_{3} \mathrm{NH}_{3}$ land $\mathrm{Pbl}_{2}$ powers and the mixture of $\mathrm{CH}_{3} \mathrm{NH}_{3} \mathrm{I} \cdot 3 \mathrm{CH}_{3} \mathrm{NH}_{2}$ and $\mathrm{Pbl}_{2} \cdot \mathrm{CH}_{3} \mathrm{NH}_{2}$. ${ }^{36}$

coating technology can control the distance between blade and the substrate, and the in situ thermal-treatment temperature. In 2015, S. Razza and A. D. Carlo et al. ${ }^{47}$ used the blade coating technology, which achieved a module PSCs with a $10.1 \mathrm{~cm}^{2}$ active area that had the efficiency of $10.4 \%{ }^{47}$ Meanwhile, an efficiency of $4.3 \%$ had been measured for a module area of 100 $\mathrm{cm}^{2} .^{47}$ In 2016, J. L. Yang et al. ${ }^{94}$ reported an approach to fabricate ultra-long nanowires array and highly oriented $\mathrm{CH}_{3}$ $\mathrm{NH}_{3} \mathrm{PbI}_{3}$ thin films in ambient environments, briefly, this approach included large-scale roll-to-roll micro-gravure printing and doctor blading (Fig. 16), which produced perovskite nanowires lengths as long as $15 \mathrm{~mm} .{ }^{94}$

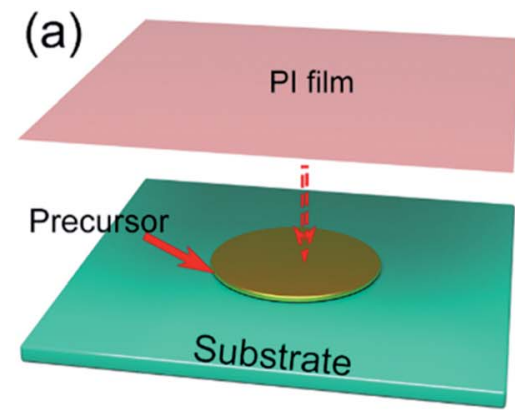

(I) Add precursor and apply PI film

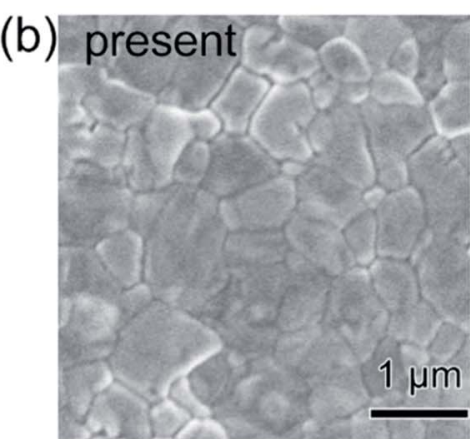

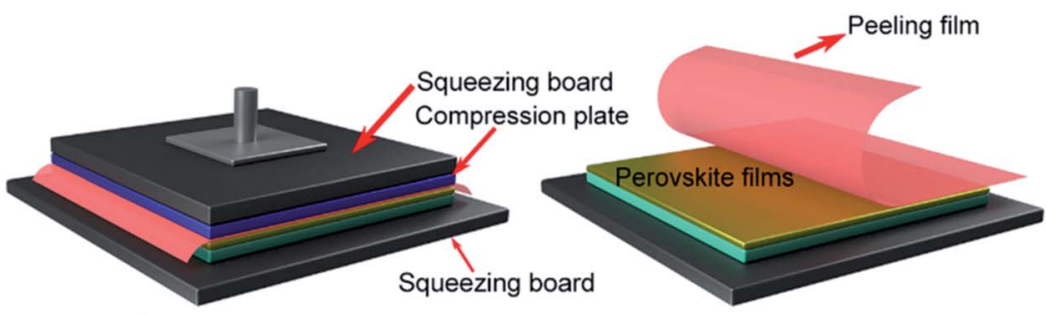

(II) Apply pressure

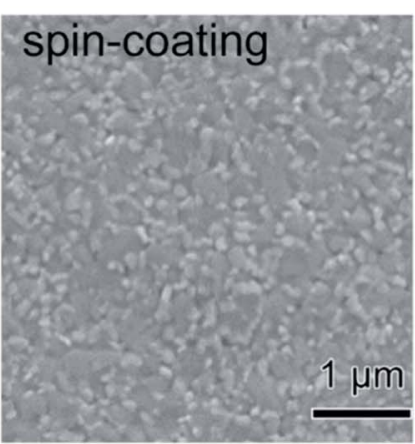

(III) Peel PI film

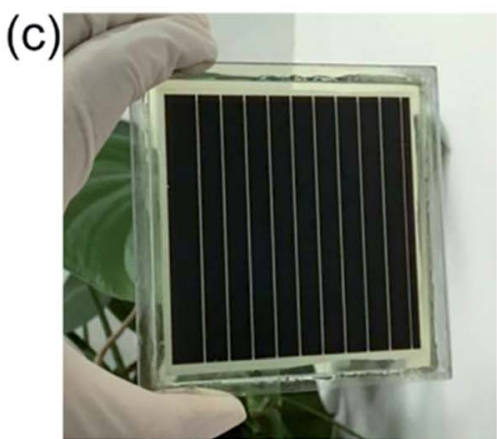

Fig. 14 Diagram of the pressure processing method for the deposition of perovskite films. (a) The steps of the pressure processing method. (b) SEM images. (c) Photograph of a perovskite module. ${ }^{36}$ 

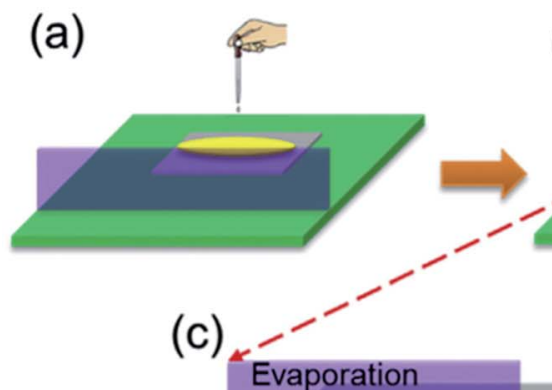

(b)

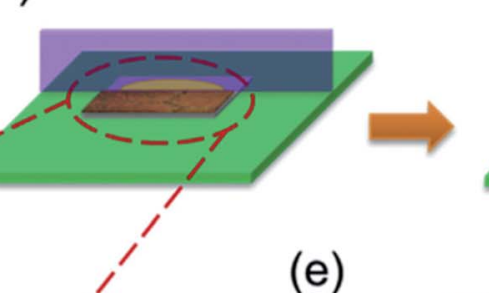

(e) (d)

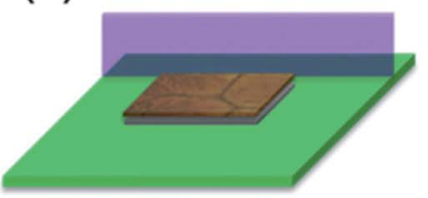

contact line

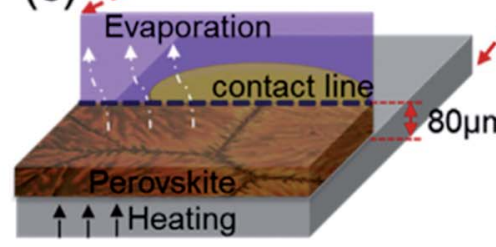

Glass substrate
$\mathrm{CH}_{3} \mathrm{NH}_{3} \mathrm{Pbl}_{3}$ solution

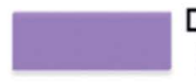

Doctor

blade
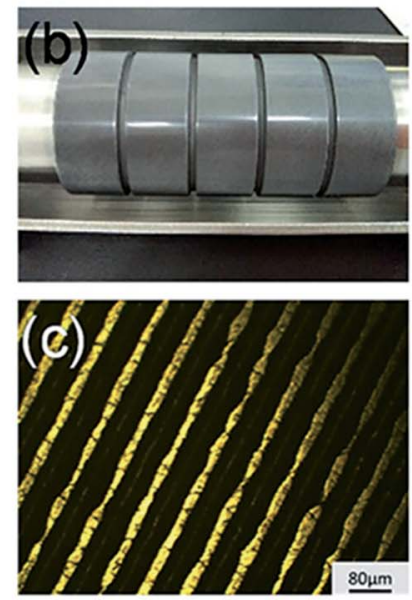

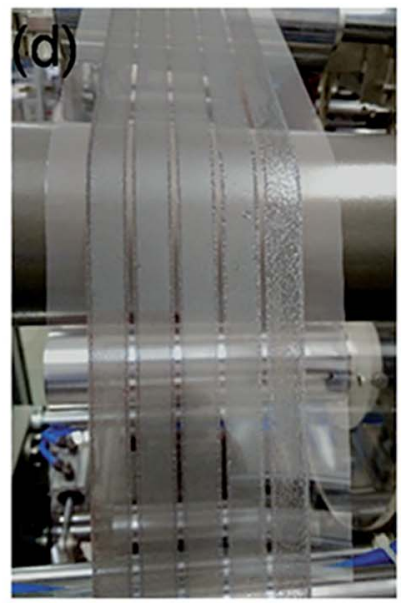

Fig. 16 (a) Photo of self-developed R2R multi-function printer. (b) Photo of micro-gravure printer roller. (c) Optical microscope image of engraved micro-gravure printer roller. (d) A photo of R2R printing process. ${ }^{94}$

\section{Methods of improving PCE for large-area $\left(\geq 1 \mathrm{~cm}^{2}\right)$ perovskite solar cells}

For the large-area PSCs device, improving the PCE, the first method is to change the chemical composition of perovskite, adjusting its band gap and increasing the charge generation. ${ }^{3,29,31,35,38,46}$ The second approach is to increase the grain size of perovskite, decreasing the cracks and pinholes, that reduces the bulk defect recombination and electric leakage, and increase $V_{\text {oc. }}{ }^{35-38}$ The third approach is interface modification, which reduces interface contact resistance, and reduce interface and surface recombination, and increase $J_{\mathrm{sc}}{ }^{\mathbf{3 1 , 4 1 , 4 5 , 9 5}}$

For the large-area PSCs device, with the increasing of cell size, the series resistance $\left(R_{\mathrm{S}}\right)$ increase among the charge transfer layers, the absorber layer and the electrode layers. At the same time, the number of the crack and the pinholes increase, that from the shunt resistance $\left(R_{\mathrm{sh}}\right)$ and the value of $R_{\mathrm{sh}}$ decrease. Incorporating these resistances into the circuit

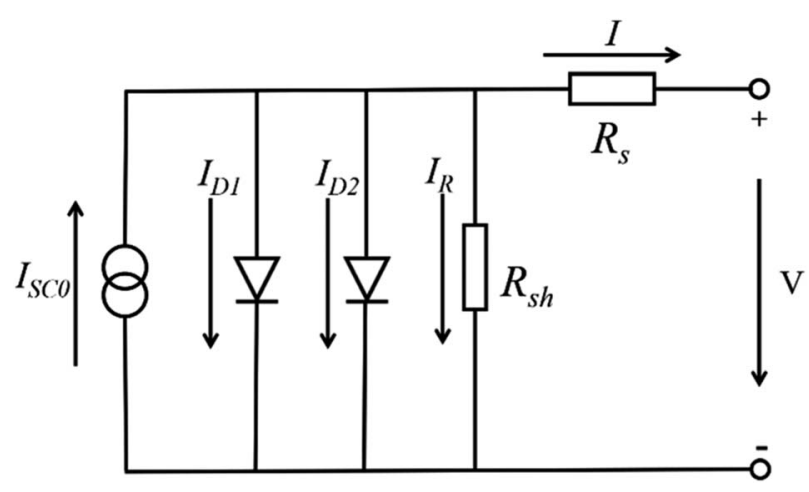

Fig. 17 Incorporating these resistances into the circuit model. ${ }^{96}$ 

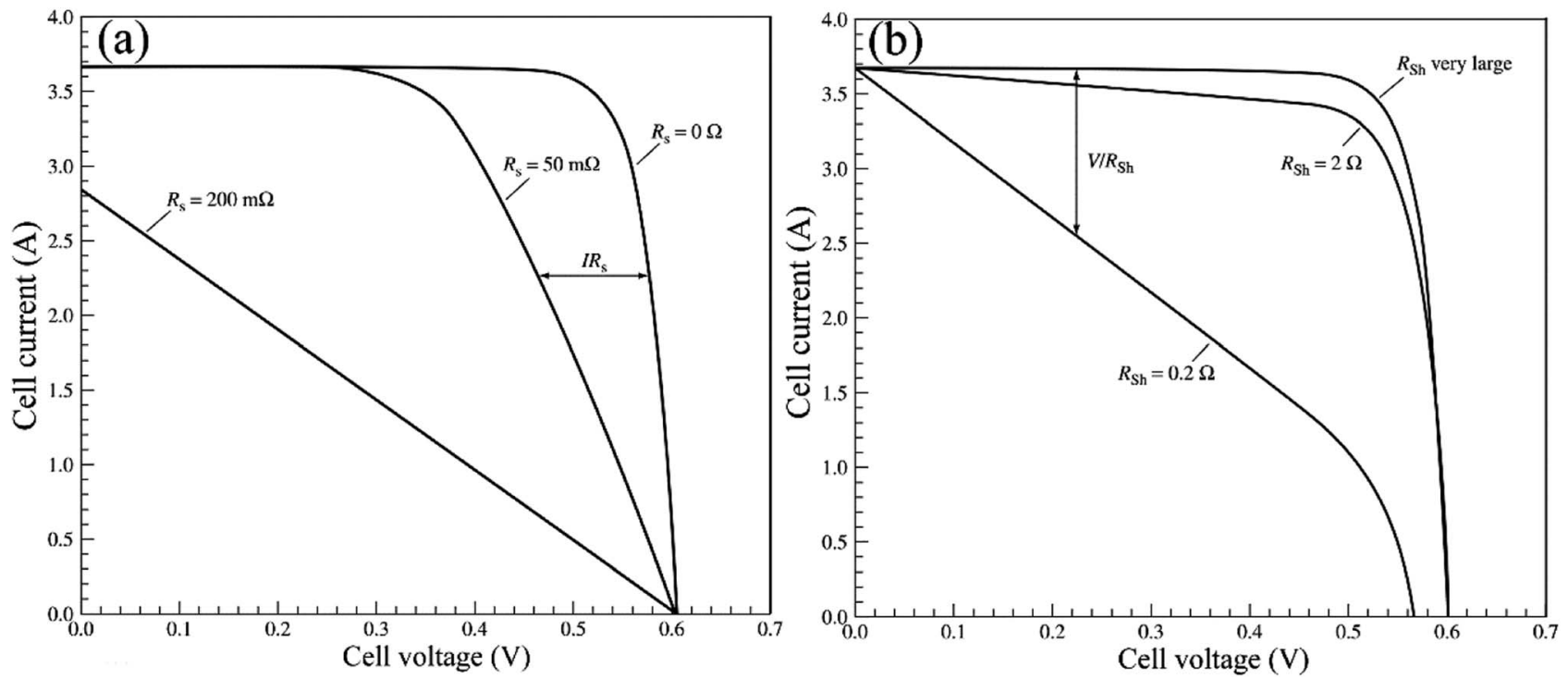

Fig. 18 (a) $I-V$ curve of $R_{\mathrm{s}^{\prime}}$ (b) $I-V$ curve of $R_{\mathrm{sh} .}{ }^{96}$

model of the solar cells device shows in Fig. 17.96 The increasing of $R_{\mathrm{S}}$ and the decreasing of $R_{\mathrm{sh}}$ increase the interface losses of the large-area PSCs device, that is the major reason of the lower efficiency for the large-area PSCs device. ${ }^{95}$

The current expression in the circuit can be written as eqn (2). ${ }^{96}$

$I=I_{\mathrm{SC} 0}-I_{\mathrm{D} 1}\left[\mathrm{e}^{q\left(V+I R_{\mathrm{s}}\right) / k T}-1\right]-I_{\mathrm{D} 2}\left[\mathrm{e}^{q\left(V+I R_{\mathrm{s}}\right) / k T}-1\right]-\frac{V+I R_{\mathrm{S}}}{R_{\mathrm{sh}}}$

where $I_{\mathrm{SCo}}$ is the short-circuit current when there are no parasitic resistances $\left(R_{\mathrm{S}}\right.$ and $\left.R_{\mathrm{sh}}\right)$. The effect of these parasitic resistances on the $I-V$ characteristic is shown in Fig. 18. Form the eqn (2), the series resistance, $R_{\mathrm{S}}$ increase, has no effect on the open-circuit voltage, but reduces the short-circuit current $\left(J_{\text {sc }}\right)$ and fill factor (FF) (Fig. 18(a)). Conversely, the shunt resistance, $R_{\mathrm{sh}}$ decrease, has no effect on the short circuit current, but reduces the open-circuit voltage $\left(V_{\mathrm{oc}}\right)$ and $\mathrm{FF}$ (Fig. 18(b)).

\subsection{Chemical molecular engineering}

For the perovskite material, its band gap can regulate via exchange the chemical molecular or element, achieving an ideal band gap of the perovskite material. Such as, through intramolecular exchange, formamidinium (FA) molecular is frequently used to replace methylamine (MA) in $\mathrm{MAPbI}_{3}$, forming $\mathrm{FAPbI}_{3}$ and adjusting the band gap. In 2015, W. S. Yang and J. H. Noh et al..$^{29}$ have fabricated $\mathrm{FAPbI}_{3}$ films, its band gap is $1.47 \mathrm{eV}$ smaller than $\mathrm{MAPbI}_{3}(1.50 \mathrm{eV})$. Meanwhile, the PCE of FAPbI $_{3}$-based PSCs is up to $20.1 \%$. In 2017, J. Y. Kim and D. S. Kim et al..$^{35}$ fabricated $\left(\mathrm{FAPbI}_{3}\right)_{0.85}\left(\mathrm{MAPbBr}_{3}\right)_{0.15}(1.55 \mathrm{eV})$ as absorber layer of the PSCs device, which had a maximum PCE exceeding $18 \%$ over a $1 \mathrm{~cm}^{2}$ active area. In 2017, E. K. Kim, J. H. Noh and S. I. Seok et al. ${ }^{3}$ introduced additional iodide ions into the organic cation solution, that decreased the concentration of deeplevel defects. They fabricated of the $\left(\mathrm{FAPbI}_{3}\right)_{x}\left(\mathrm{MAPbBr}_{3}\right)_{1-x}$-based PSCs with a certified PCE of $19.7 \%$ in $1 \mathrm{~cm}^{2}$ cells. ${ }^{3}$ Adding inorganic cesium to triple-cation perovskite compositions, E. H. Sargent et al. ${ }^{31}$ have reported the best-performance large-area $\left(1.1 \mathrm{~cm}^{2}\right)$ PSCs $\left(\mathrm{Cs}_{0.05} \mathrm{FA}_{0.81} \mathrm{MA}_{0.14} \mathrm{PbI}_{2.55} \mathrm{Br}_{0.45}, 1.60 \mathrm{eV}\right)$, that has a PCE of 20.3\%. In 2017, X. W. Zhang and J. B. You et al. ${ }^{38}$ used the $\left(\mathrm{FAPbI}_{3}\right)_{1-x}\left(\mathrm{MAPbBr}_{3}\right)_{x}(1.55 \mathrm{eV})$ as absorber layer for PSCs with the certified efficiency of $20.1 \%$ in large-area $\left(1 \mathrm{~cm}^{2}\right) .{ }^{38}$

\subsection{Improving preparation technology}

The high quality (cracks- and pinholes-free) large-area perovskite film is precondition for the achieving high PCE of PSCs. Because the cracks and pinholes can form electric leakage (forming the $R_{\mathrm{sh}}$ ), which lead to the decreasing the $V_{\mathrm{oc}}$ and $\mathrm{FF}$, and reduce the PCE of PSCs. So, M. J. Kim and G. H. Kim et al. ${ }^{35}$ developed one step spin-coating, and using high-temperature short-time annealing process (Fig. 7(a)), achieving the perovskite grains with sizes more than $1 \mu \mathrm{m}$ without pinhole (HTSA400, Fig. $7(\mathrm{~d}, \mathrm{e}, \mathrm{h}$ and i)). They fabricated PSCs device with 1 $\mathrm{cm}^{2}$, which achieved the PCE of $18.32 \%$ with HTSA-400 (Fig. 19(d)), but the PCE is only $13.82 \%$ with HTSA-100 (Fig. 19(c))..$^{35} \mathrm{X}$. Li and M. Grätzel et al. ${ }^{37}$ used the vacuum flash-assisted solution processing (VASP) to fabricate perovskite film (Fig. 8(a)), the sizes of perovskite grains were between 400 and $1000 \mathrm{~nm}$ (Fig. 8(c)). They fabricated the PSCs device with an aperture area exceeding $1 \mathrm{~cm}^{2}$, the certified PCE of $19.6 \%{ }^{37}$ In 2015, Z. Zhou, S. Pang, G. Cui et al. ${ }^{93}$ reported that the MA gas treatment has been introduced to create smooth, uniform and full coverage $\mathrm{MAPbI}_{3}$ thin films (Fig. $\left.12(\mathrm{c})\right)^{93} \mathrm{This} \mathrm{MAPbI}_{3}$ was used to fabricate the PSCs device, the PCE increased from 5.7\% to $15.1 \%$, was observed, which was clearly the result of the improving film morphology. ${ }^{93}$

\subsection{Interface engineering}

Interface engineering can optimize interface contact, mitigate carrier recombination and increase carrier collection, which is extremely important to achieve high-performance and high- 
(a)

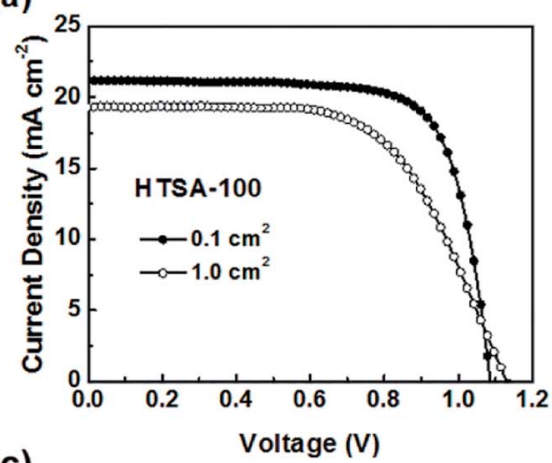

(c)

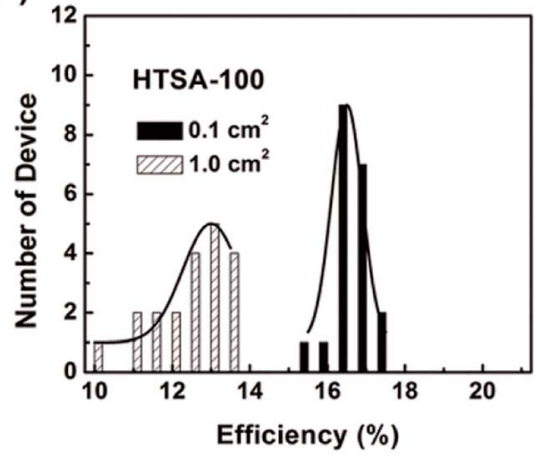

(b)

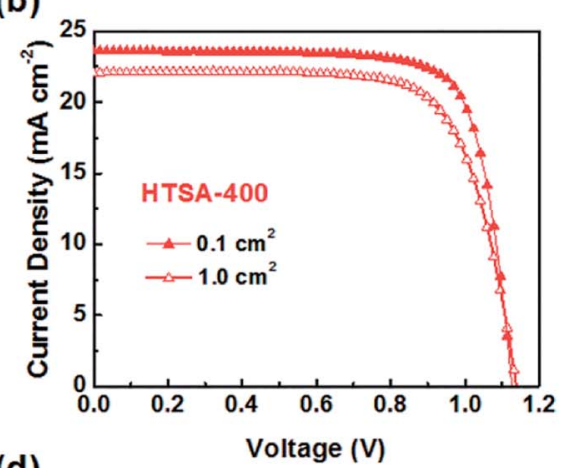

(d)

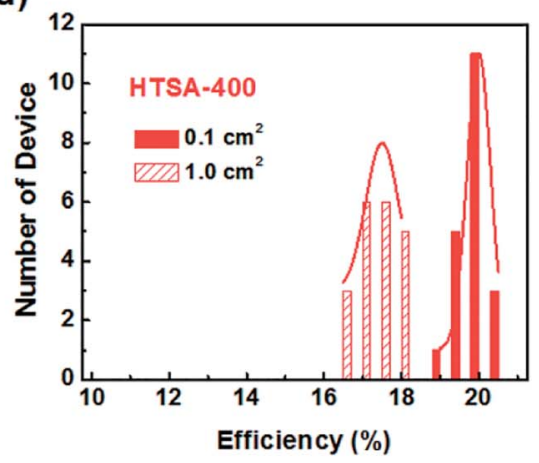

Fig. 19 (a) Current-voltage curves of perovskite solar cells derived from HTSA-100 and (b) HTSA-400 with an active area $0.1 \mathrm{~cm}^{2}$ and a $1 \mathrm{~cm}^{2}$. (c) Histogram of PCEs derived from HTSA-100 and (d) HTSA-400 with an active area $0.1 \mathrm{~cm}^{2}$ and $1 \mathrm{~cm}^{2} .35$

stability PSCs. Interface engineering includes doped, plasma etching, self-assembled monolayers and interface buffer layer etc.

Doping for the charge transport layers, that can improve their electrical performance, such as improving carrier concentration and mobility. For $\mathrm{Li}-\mathrm{Mg}$ co-doped NiO films, the conductivity is $2.32 \times 10^{-3} \mathrm{~S} \mathrm{~cm}^{-1}, \sim 12$ times greater than that of the pure $\mathrm{Mg}_{x} \mathrm{Ni}_{1-x} \mathrm{O}^{41}$ The conductivity of $\mathrm{Nb}^{5+}$ doped $\mathrm{TiO}_{2}$ films is $\sim 10^{4} \mathrm{~S} \mathrm{~cm}^{-1}, \sim 100$ to 1000 times greater than that of the pure $\mathrm{TiO}_{2}{ }^{41}$ In 2015, M. Grätzel and L. Y. Han et al. ${ }^{41}$ have used $\mathrm{Mg}$-Li co-doped NiO as HTL and $\mathrm{Nb}$ doped $\mathrm{TiO}_{x}$ as ETL material in inverted planar PSCs to achieve very rapid carrier extraction, increasing the cell FF from 0.64 to 0.827 . Meanwhile, they fabricated a large-area $\left(>1 \mathrm{~cm}^{2}\right)$ PSCs (Fig. 20 (a)) with a certified efficiency of $15 \%{ }^{41}$ The contact-passivation can mitigate interfacial recombination and improve interface binding in lowtemperature planar PSCs. H. R. Tan and E. H. Sargent et al. ${ }^{31}$ reported a contact-passivation strategy using chlorine-capped $\mathrm{TiO}_{2}\left(\mathrm{Cl}-\mathrm{TiO}_{2}\right)$ colloidal nanocrystal film as ETL, the chargerecombination lifetime increased from $64 \mu \mathrm{s}$ to $145 \mu \mathrm{s}$ compare with pure $\mathrm{TiO}_{2}$ film. ${ }^{31}$ They fabricated the planar PSCs for active areas of $1.1 \mathrm{~cm}^{2}$, that achieved a certified efficiency of $19.5 \%$ without hysteresis. ${ }^{31}$ Interlayers are thin layers or monolayers of organic molecules that modify a specific interface in the solar cell. ${ }^{97}$ In 2016, C.Y. Chang and Y. C. Chang et al. ${ }^{45}$ reported an approach for the modification of interface layer via introducing thiol-functionalized self-assembled monolayers (SAMs, Fig. 21(b)), which decreased interface charge recombination and increased the value of $J_{\mathrm{sc}}\left(19.43 \mathrm{~mA} \mathrm{~cm}{ }^{-2}\right.$ to
$21.68 \mathrm{~mA} \mathrm{~cm}^{-2}$ ) and FF (0.67 to 0.72). They fabricated a large-area $\left(1.2 \mathrm{~cm}^{2}\right)$ PSCs with the PCE up to $15.98 \%{ }^{45} \mathrm{Y}$. Wu and X. Yang et $a l^{42}$ reported a perovskite-fullerene graded heterojunction structure, which improved the photoelectron collection and reduced recombination loss. They fabricated the PSCs of 1.022 $\mathrm{cm}^{2}$, that had a certified PCE of $18.21 \%{ }^{42}$

\section{Stability of large-area $\left(\geq 1 \mathrm{~cm}^{2}\right)$ perovskite solar cells}

In recent years, the certificated PCE of the large-area $\left(1 \mathrm{~cm}^{2}\right)$ PSCs has achieved $20.1 \%{ }^{38}$ However, the major issue of largearea PSCs for commercial applications is the poor long-term device stability. For the stability of the perovskite materials and devices, it is necessary to consider the effects of temperature, illumination and ambient (oxygen, moisture) exposure. Many papers have reported about this important issue..$^{\mathbf{1 , 5 1 , 5 3 , 9 7 - 1 0 7}}$

\subsection{Degradation mechanisms}

The degradation of the PSCs device includes the degradation of the active layer, the degradation of charge transport layers, and the degradation of electrodes. ${ }^{104}$ The MAPI ${ }_{3}$ films are frequently used as absorber layer film. But the major problem with $\mathrm{MAPbI}_{3}$ is that has thermal decomposition (exceeding $85^{\circ} \mathrm{C}$ ) ${ }^{108,109}$ and water decomposition..$^{1,48,110}$ Some researchers have reported the decomposition process of $\mathrm{MAPbI}_{3}$. B. Philippe and H. Rensmo et al. ${ }^{109}$ exposed the $\mathrm{MAPbI}_{3}$ and $\mathrm{MAPbI}_{3-x} \mathrm{Cl}_{x}$ to various environments. From the photoelectron spectroscopy results with 


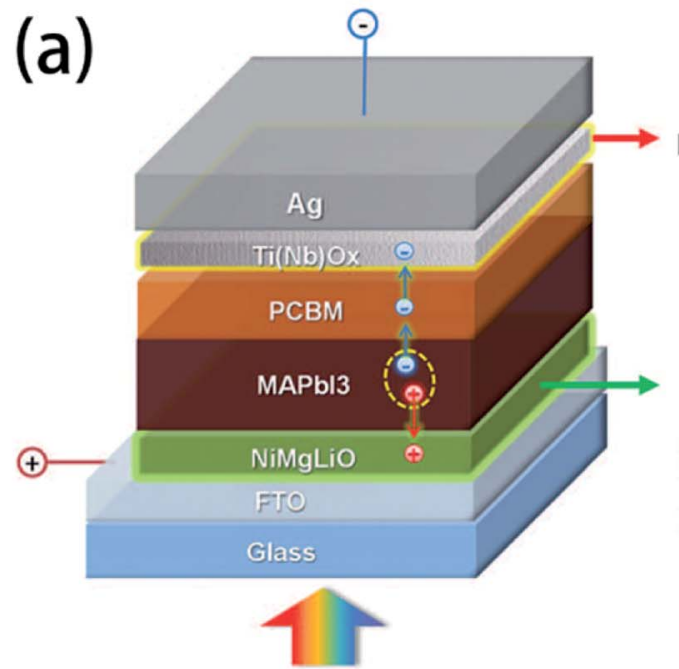<smiles></smiles><smiles>[R]O[N+]([R20])([R20])O[R]</smiles><smiles></smiles>

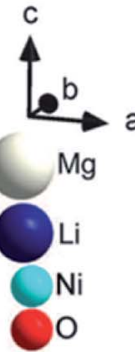

$\mathrm{Ti}(\mathrm{Nb}) \mathrm{Ox}$
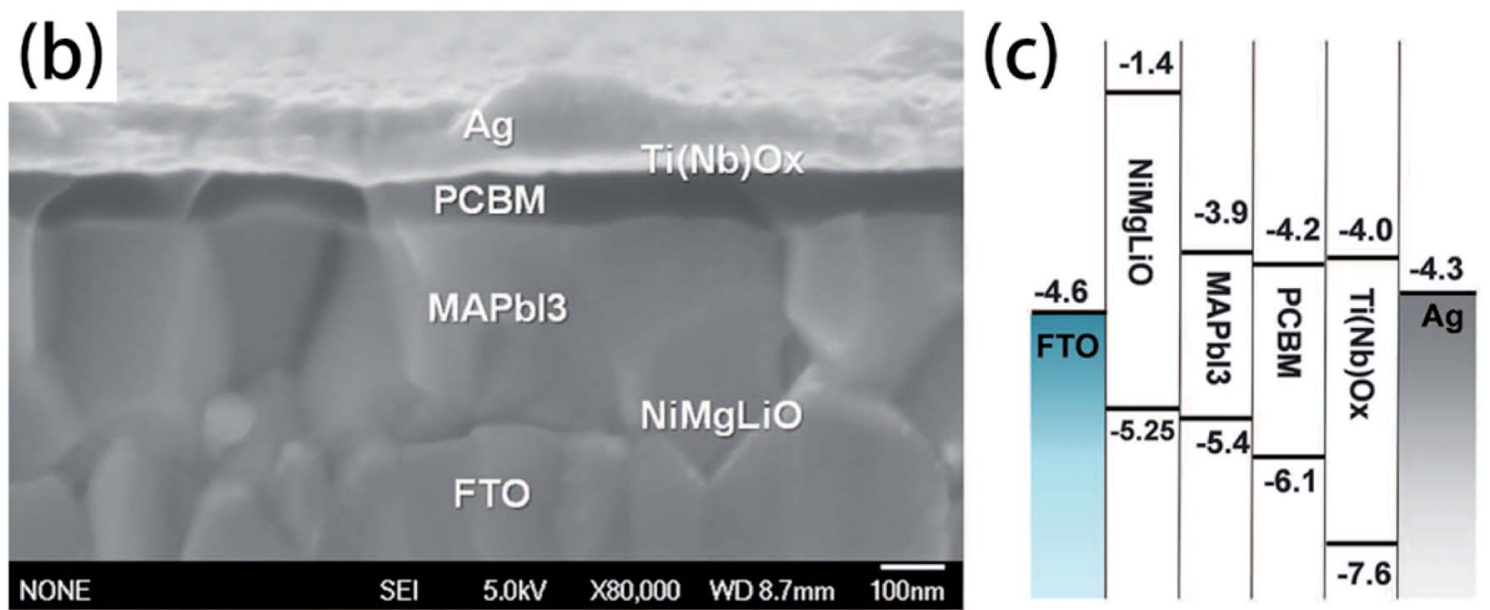

Fig. 20 Structure and band alignments of the PSCs, (a) diagram of the cell configuration highlighting the doped charge carrier extraction layers. (b) A high-resolution cross-sectional SEM image of a complete solar cell. (c) Band alignments of the solar cell. ${ }^{41}$

the different environments, the perovskite has decomposed into $\mathrm{PbI}_{2}$, but this degradation seems to occur already at $100{ }^{\circ} \mathrm{C}$ and is not only related to large humidity (Fig. 22(a)). Meanwhile, they observed a slow degradation occurs even when stored in an inert atmosphere such as argon. ${ }^{109} \mathrm{~L}$. D. Wang et al. ${ }^{48}$ verified that oxygen, together with moisture, could lead to the irreversible degradation of MAPbI 3 . They exposed $\mathrm{TiO}_{2} / \mathrm{CH}_{3} \mathrm{NH}_{3} \mathrm{PbI}_{3}$ film to air with a humidity of $60 \%$ at $35{ }^{\circ} \mathrm{C}$ for $18 \mathrm{~h}$, and then, the absorption between 530 and $800 \mathrm{~nm}$ greatly decreased (Fig. 22(b)), the $\mathrm{MAPbI}_{3}$ decomposed into $\mathrm{PbI}_{2}$ and $\mathrm{I}_{2}$ (Fig. 21(c)). ${ }^{48}$ The degradation mechanism of $\mathrm{MAPbI}_{3}$ upon exposure to moisture in absence of illumination involves the formation of hydrate form, which can be reversible. .1,48,111,112 $^{2}$ However, continuing exposure to moisture and/or exposure to illumination leads to the irreversible degradation to $\mathrm{PbI}_{2}{ }^{111}$ For ETL material, $\mathrm{TiO}_{2}$ is especially sensitive to ultraviolet light, in the ultraviolet light, $\mathrm{Ti}^{4+}$ adsorb $\mathrm{O}_{2}$ and convert into $\mathrm{Ti}^{3+}$, increasing the charge recombination. ${ }^{113}$ Meanwhile, the lithium salt in spiro-MeOTAD is easy to absorb moisture and decrease the PSCs device stability.

\subsection{Methods of improving stability}

In recent years, many methods have been researched to improve the PSCs device stability. Due to the poor stability of $\mathrm{MAPI}_{3}$, the first method is to modify the chemical constituents or structure of the perovskite. For example, 2D perovskites, compared with 3D perovskites, 2D perovskites have the higher carrier mobility while maintaining good ambient stability. ${ }^{14,115}$ The 2D Ruddlesden-Popper layered perovskites $\left((\mathrm{BA})_{2}(\mathrm{MA})_{2} \mathrm{~Pb}_{3} \mathrm{I}_{10}\right.$ and $\left.(\mathrm{BA})_{2}(\mathrm{MA})_{3} \mathrm{~Pb}_{4} \mathrm{I}_{13}\right)$ have been studied (Fig. 23(a)). ${ }^{115}$ The $(\mathrm{BA})_{2}(\mathrm{MA})_{3} \mathrm{~Pb}_{4} \mathrm{I}_{13}$ film color gets darker with increasing temperature (Fig. 23(b)). ${ }^{115} \mathrm{H}$. Tsai and W. Nie et al. ${ }^{115}$ have achieved a PCE of $12.51 \%$ with $2 \mathrm{D}(\mathrm{BA})_{2}(\mathrm{MA})_{3} \mathrm{~Pb}_{4} \mathrm{I}_{13}$ PSCs device. Under the constant light illumination, after $2500 \mathrm{~h}$, the 2D perovskite devices is retaining $70 \%$ of its original PCE without encapsulated and $98 \%$ with encapsulated. The 3D perovskite devices have degraded $<10 \%$ of its original PCE after 2500 h (Fig. 24(a and c)). Fig. 24(b) shows the PCE of the unencapsulated $2 \mathrm{D}$ and $3 \mathrm{D}$ devices, that shows degradation after $60 \mathrm{~h}$, under $65 \%$ relative humidity. ${ }^{115}$ With simple encapsulation, after $2500 \mathrm{~h}$, the $2 \mathrm{D}$ devices retained $80 \%$ of its original PCE under $65 \%$ relative humidity, but the 3D devices had 
(a)

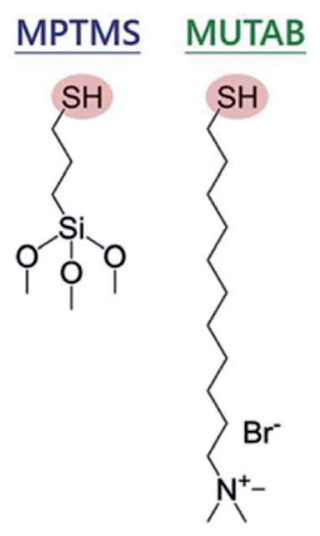

(b)

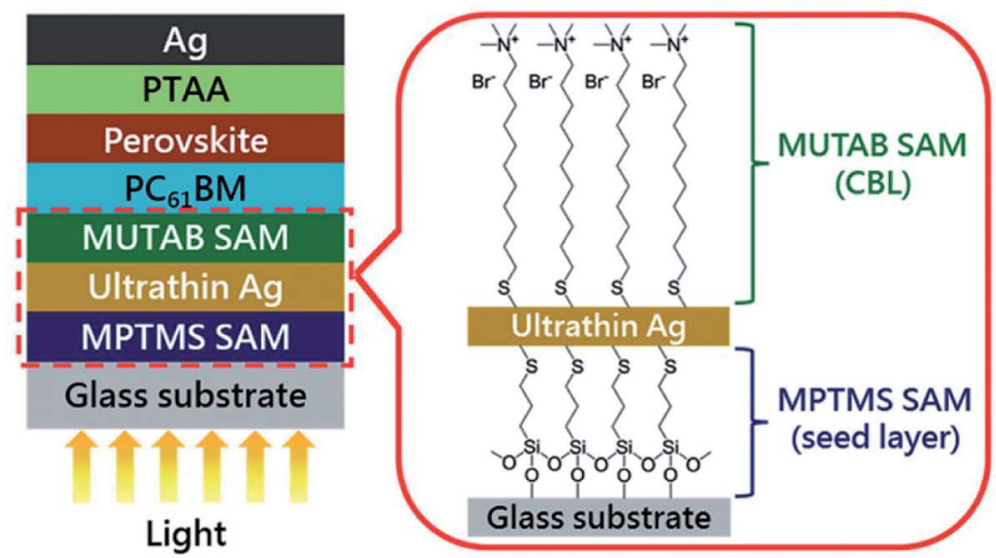

Fig. 21 (a) Chemical structures of SAM molecules. (b) Schematic illustration of the device architecture used in this study. ${ }^{45}$
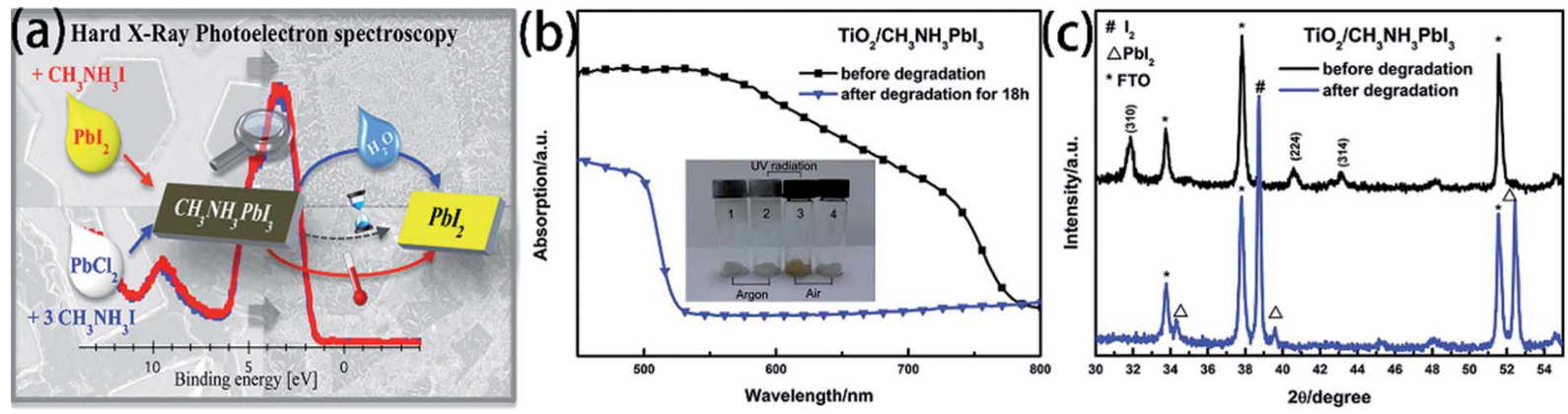

Fig. 22 (a) Degradation of $\mathrm{MAPb}_{3}$ in moisture and air atmosphere. ${ }^{109}$ (b) UV-vis absorption spectra of $\mathrm{TiO}_{2} / \mathrm{MAPbl}_{3}$ film before and after degradation. ${ }^{48}$ (c) XRD patterns of $\mathrm{TiO}_{2} / \mathrm{MAPb}_{3}$ film before and after degradation. ${ }^{48}$

(a)

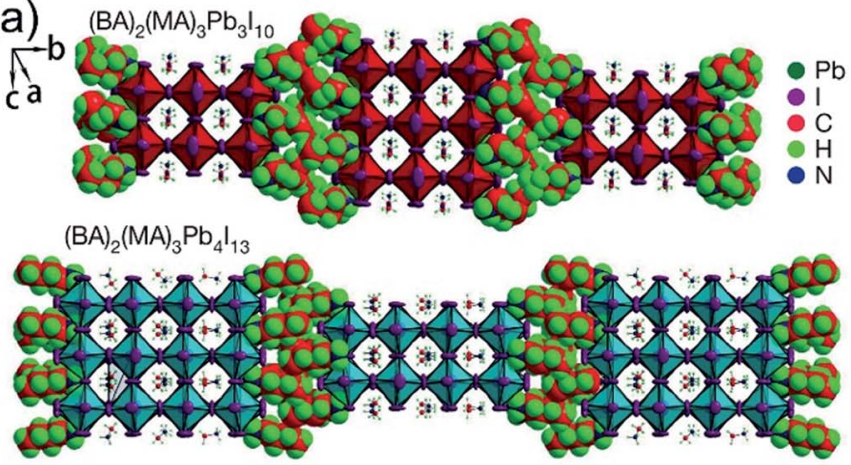

(b)

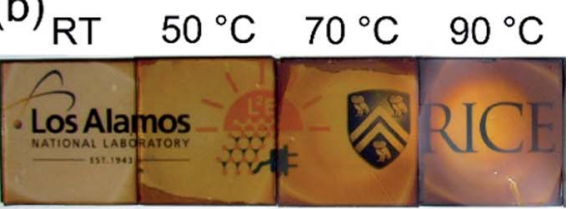

$110^{\circ} \mathrm{C} 130^{\circ} \mathrm{C} \quad 150^{\circ} \mathrm{C}$

Fig. 23 Crystal structure and thin-film characterization of layered perovskites. (a) The crystal structure of the Ruddlesden-Popper $(\mathrm{BA})_{2}(\mathrm{MA})_{2} \mathrm{~Pb}_{3} \mathrm{I}_{10}$ and $(\mathrm{BA})_{2}(\mathrm{MA})_{3} \mathrm{~Pb}_{4} \mathrm{I}_{13}$ layered perovskites. (b) Photos of $(\mathrm{BA})_{2}(\mathrm{MA})_{3} \mathrm{~Pb}_{4} \mathrm{I}_{13}$ thin films cast from room temperature $(\mathrm{RT})$ to $150{ }^{\circ} \mathrm{C}$. ${ }^{115}$

been degraded (Fig. 24(d)). ${ }^{115}$ K. Yao et $a .^{46}$ used the polyethylenimine (PEI) cations to fabricate the 2D perovskite compounds $(\mathrm{PEI})_{2}(\mathrm{MA})_{n-1} \mathrm{~Pb}_{n} \mathrm{I}_{3 n+1}(n=3,5,7)$, which was used as absorber layer to fabricate PSCs with an aperture area of 2.32 $\mathrm{cm}^{2}$ under ambient humidity that have a PCE up to $8.77 \%$. After $500 \mathrm{~h}$, the PCE of the 2D large-area PSCs device only decreased by $\sim 5 \% .^{46}$
Furthermore, the alkali metal cation is introduced into the perovskite material, which can improve the stability of the PSCs device. ${ }^{31,68,116}$ E. H. Sargent et $a l^{31}$ added cesium cation to fabricate a triple-cation perovskite compositions films $\left(\mathrm{Cs}_{0.05}{ }^{-}\right.$ $\left.\mathrm{FA}_{0.81} \mathrm{MA}_{0.14} \mathrm{PbI}_{2.55} \mathrm{Br}_{0.45}\right)$, that was made the large-area (1.1 $\mathrm{cm}^{2}$ ) PSCs with a PCE up to $20.3 \%$ (Fig. 25(b and c)). After 90 days, the PSCs devices retained $96 \%$ of its initial PCE (Fig. 25(a)). ${ }^{31}$ Rubidium (Rb) cations can stabilize the black 

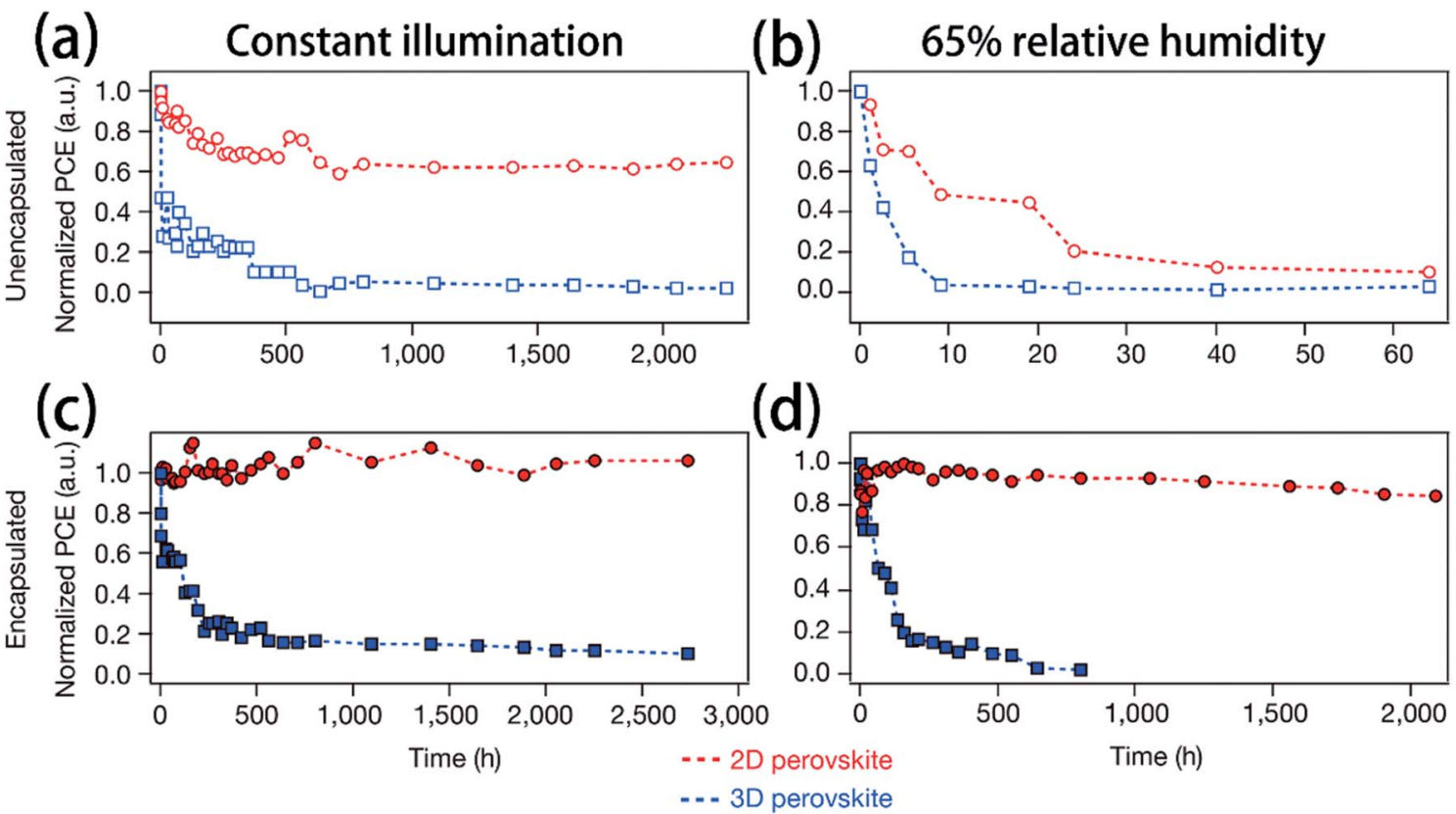

Fig. 24 (a and c) Photostability tests under constant AM1.5G illumination for 2D ((BA) $2(M A)_{3} \mathrm{~Pb}_{4} \mathrm{l}_{13}$; red) and 3D (MAPbl 3 ; blue) perovskite devices. ( $b$ and $d$ ) Humidity stability tests under $65 \%$ relative humidity at in a humidity chamber for $2 \mathrm{D}\left((\mathrm{BA})_{2}(\mathrm{MA})_{3} \mathrm{~Pb} 4 \mathrm{I}_{13} ;\right.$ red) and $3 \mathrm{D}\left(\mathrm{MAPb} \mathrm{I}_{3}\right.$; blue) perovskite devices. ${ }^{115}$

phase of FA perovskite and be integrated into PSCs, M. Saliba and M. Grätzel et al. ${ }^{116}$ have used RbCsMAFAPbI ${ }_{3}$ as absorber layer of the PSCs device. After $500 \mathrm{~h}$ at $85^{\circ} \mathrm{C}$ under continuous illumination, the device has retained $95 \%$ of its initial PCE (Fig. 26(d)). ${ }^{116}$
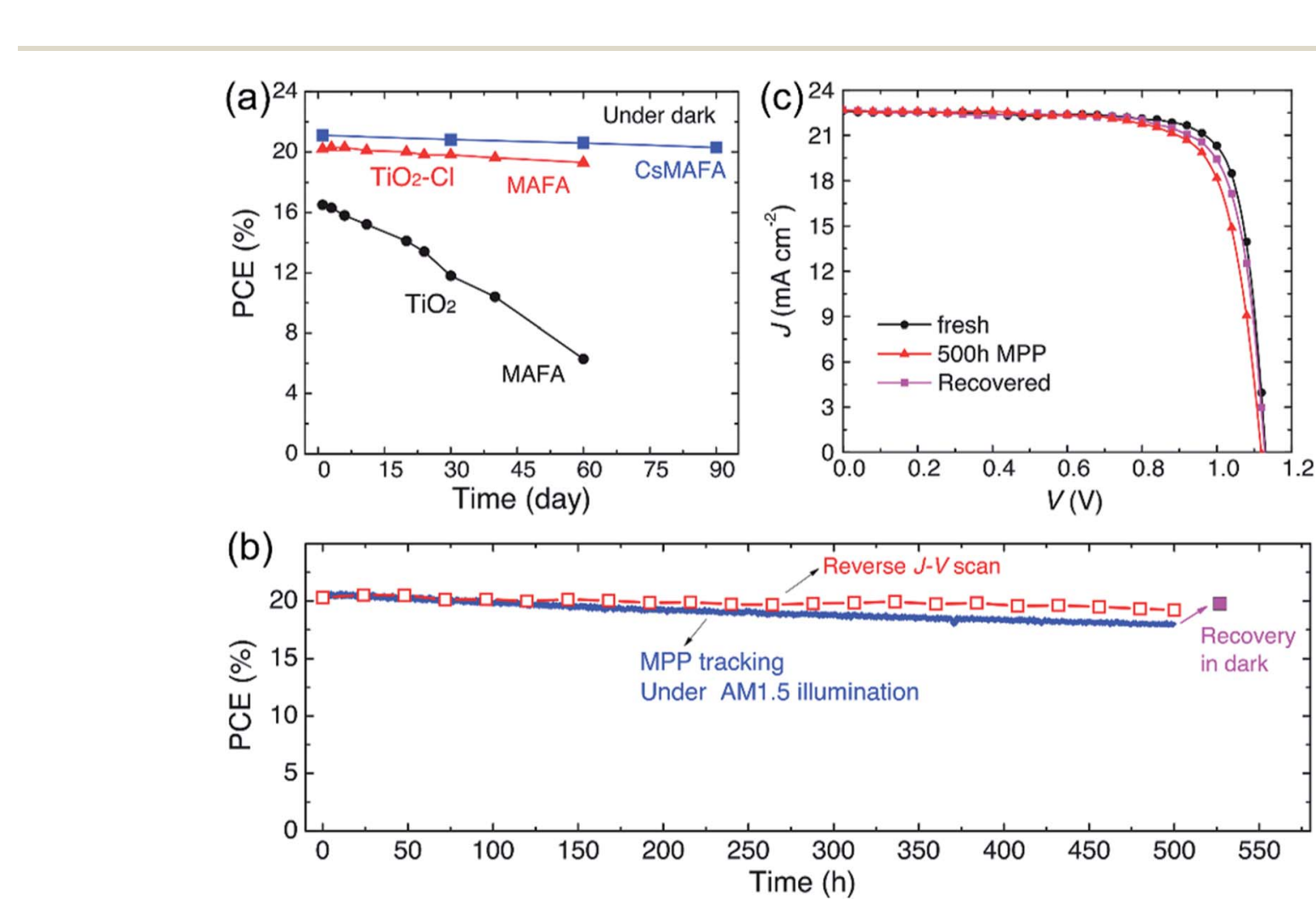

Fig. 25 Long-term device stability of PSCs with $\mathrm{TiO}_{2}-\mathrm{Cl}$ and $\mathrm{TiO}_{2}$. (a) Dark storage stability of non-encapsulated PSCs. (b) Continuous maximum power point tracking for 500 hours of a high performance unsealed CsMAFA cell with $\mathrm{TiO}_{2}-\mathrm{Cl}$ in nitrogen atmosphere under constant simulated solar illumination. (c) $J-V$ curves of the PSCs (CSMAFA) from (b) at various stages. ${ }^{31}$ 
(a)

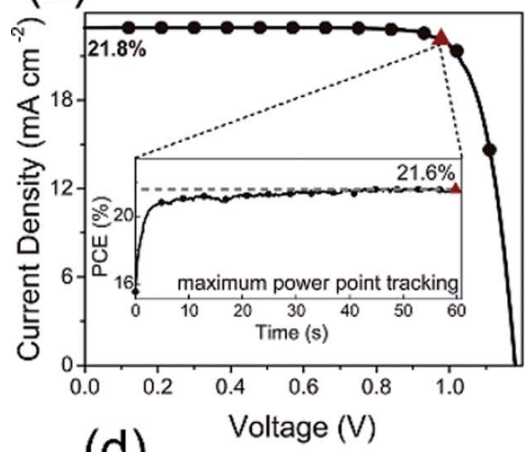

(b)

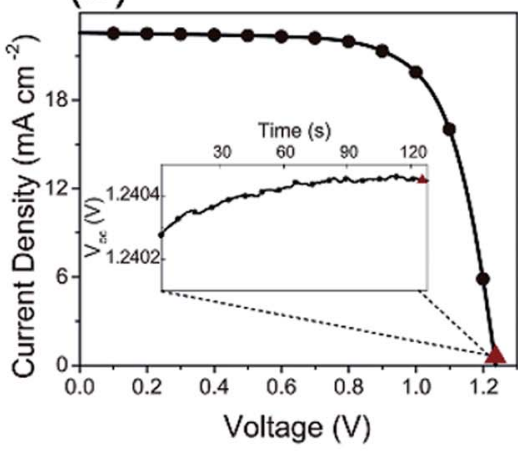

(c)

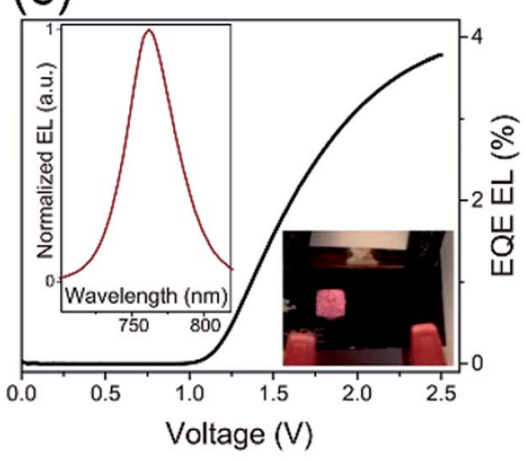

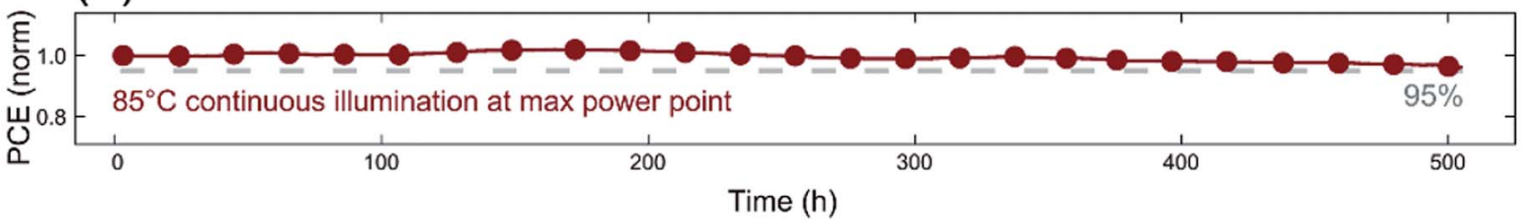

Fig. 26 (a) $J-V$ curve of RbCsMAFA solar cell. (b) $J-V$ curve of the highest- $V_{\text {oc }}$ device. (c) EQE electroluminescence (EL) as a function of voltage. (d) Thermal stability test of a perovskite solar cell. ${ }^{116}$

The second method for improving the PSCs device stability is to modify the charge transport layer (ETL and HTL), or use the new type charge transport material. ${ }^{61}$ Because $\mathrm{TiO}_{2}$ is especially sensitive to ultraviolet light, ${ }^{\mathbf{1 1 3}}$ some new ETL materials have been reported. A. D. Carlo et al. ${ }^{117}$ reported an additional lithium-neutralized graphene oxide (GO-Li) layer as interface layer was inserted between $\mathrm{TiO}_{2}$ ETL and perovskite layer, that improved the stability of PSCs devices. ${ }^{117}$ A. Hagfeldt et al. ${ }^{118}$ has used $\mathrm{ZnO}$ nanorod arrays as ETL replace the $\mathrm{TiO}_{2}$, achieving the PSCs device, it has been exposed in atmospheric environment without encapsulation, and maintaining $90 \%$ of the original efficiency. X. W. Zhang and J. B. You et al. ${ }^{57}$ have used $\mathrm{SnO}_{2}$ as ETL for planar-structure PSCs, it is found that the devices can maintain almost their original efficiency when store in dry air conditions for 40 days. ${ }^{57} \mathrm{~J}$. H. Noh and S. I. Seok et al. ${ }^{66}$ used Ladoped $\mathrm{BaSnO}_{3}$ as ETL, the PSCs retained 93.3\% of its initial PCE
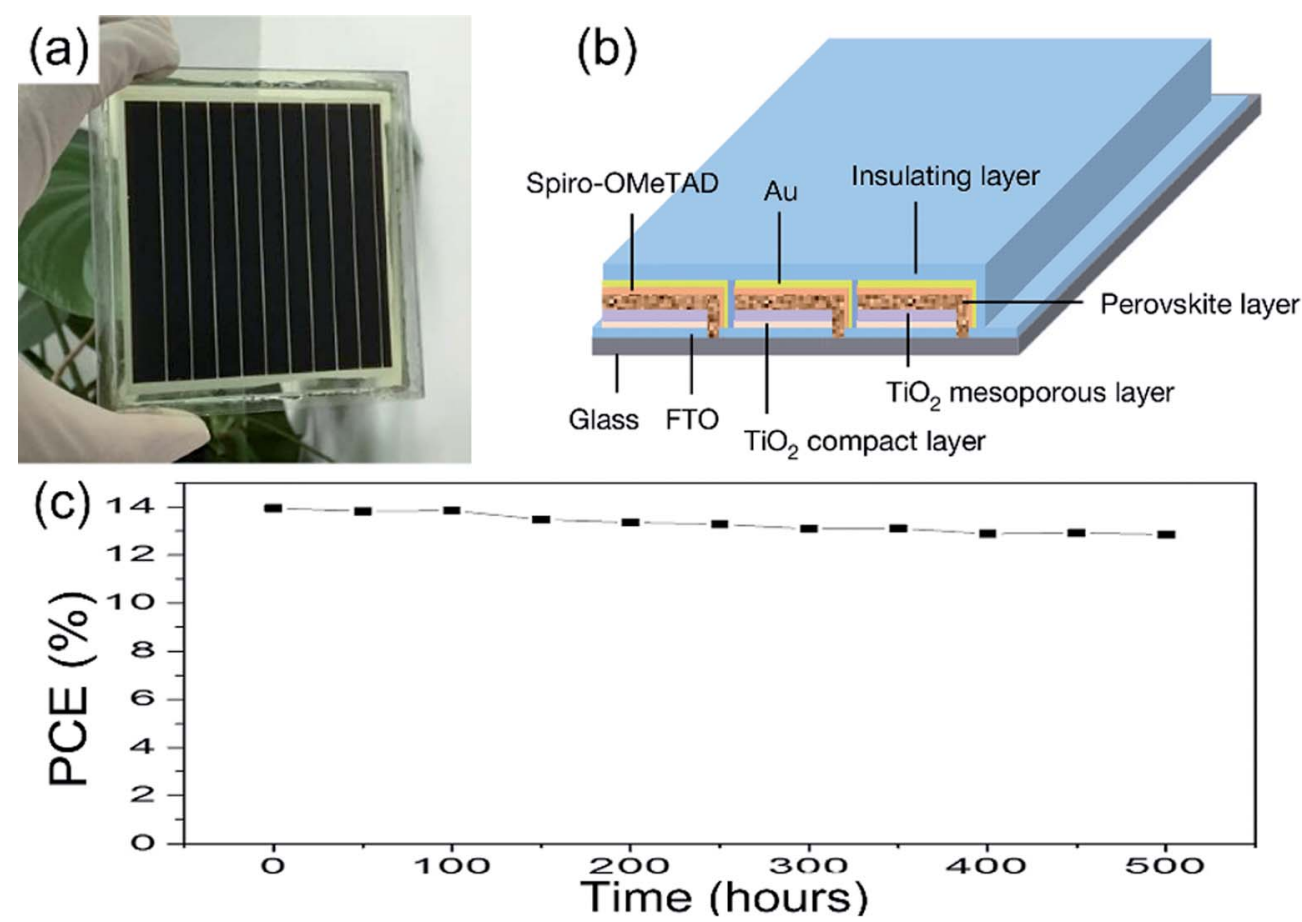

Fig. 27 Illustration of the perovskite module and device performance. (a) Photograph of a module. (b) Diagram of the module structure. (c) Evolution of the photovoltaic stability of an encapsulated perovskite solar module. ${ }^{36}$ 
after 1000 hours, whereas the $\mathrm{TiO}_{2}$ cells had completely degraded within 500 hours.

For the HTL materials, spiro-OMeTAD is the most commonly used HTL material, ${ }^{35,57,67}$ the certified PCE of $22.1 \%$ in small cell. ${ }^{3}$ But the lithium salt in spiro-MeOTAD is easy to absorb moisture and reduce the PSCs device stability. So inorganic and hydrophobic hole transport material are used to improve the

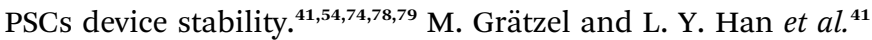
used $\mathrm{Li}_{0.05} \mathrm{Mg}_{0.15} \mathrm{Ni}_{0.8} \mathrm{O}$ as HTL material and $\mathrm{Ti}(\mathrm{Nb}) \mathrm{O}_{x}$ as ETL to fabricate inverted planar heterojunction structure device $(\mathrm{p}-\mathrm{i}-$ $\mathrm{n})$, under simulated solar light, the PSCs device maintained $90 \%$ of the original efficiency after $1000 \mathrm{~h}$. S. H. Yang et al. ${ }^{79}$ has fabricated inverted planar heterojunction structure for $\mathrm{NiO}$ based PSCs device (p-i-n), achieving more than $85 \%$ of its original PCE has been kept after 150 days. Z. B. He et al. ${ }^{78}$ used $\mathrm{NiO}_{x}$ nanocrystal as HTL in planar PSCs device. After $1000 \mathrm{~h}$, the PCE of PSCs device maintained $87 \%$ of its initial value. N. Arora and M. Grätzel et al. ${ }^{74}$ used one new HTL material CuSCN. They achieved the PSCs with PCE $>20 \%$, after 1000 hours at $60{ }^{\circ} \mathrm{C}$, the PSCs devices retained $>95 \%$ of their initial efficiency. $\mathrm{CuGaO}_{2}$ as HTL in n-i-p configuration PSCs, exposing it directly to the ambient environment without encapsulation. After 30 days, it maintains $87 \%$ its initial PCE. ${ }^{54}$

Other methods for improving the PSCs device stability include the PSCs structure optimization, interface optimization, encapsulation, etc. ${ }^{\mathbf{8 1 , 8 2 , 1 1 9}} \mathrm{A}$ hole-conductor-free structure of the PSCs can achieve long-term stability. Exposing the PSCs device $\left(\mathrm{c}-\mathrm{TiO}_{2} / \mathrm{m}-\mathrm{TiO}_{2} / \mathrm{ZrO}_{2} /\right.$ carbon) under full AM 1.5 simulated sunlight over 1008 hours, the PCE maintains $100 \%$ of its initial value. ${ }^{82}$ To improve the stability of the device, the insulation material encapsulate the PSCs device is frequently used. M. Grätzel and L. Y. Han et al. ${ }^{36}$ encapsulated the largearea PSCs device $\left(36.1 \mathrm{~cm}^{2}, \mathrm{TiO}_{2}\right.$ ETL, Fig. $27(\mathrm{a}$ and b)) by the insulation material, the module retained $90 \%$ of its initial performance after $500 \mathrm{~h}$ (Fig. 27(c)).

\section{Other issues}

\subsection{Cost analysis}

For conventional solar PV technology, it need high energy and vacuum to process solar cells. Thus, these PSCs can turn-out to be a promising solution in replacing the conventional PV technology. In this section, we briefly analyze the cost for various raw materials of a $1 \mathrm{~m}^{2}$ PSCs module. Conventional PSCs device architecture is shown in Fig. 4(a), that include glass substrate, TCO (FTO), ETL $\left(\mathrm{TiO}_{2}\right)$, perovskite absorber layer $\left(\mathrm{MAPbI}_{3}\right), \mathrm{HTL}$ (spiro-OMeTAD) and metal electrode (Au). For 1 $\mathrm{m}^{2}$ conventional PSCs module, raw material utilization for cleaning, deposition of various layers and encapsulation of the module were extracted from various available literature sources and their corresponding data are included in Table $3 .^{\mathbf{1 2 0 , 1 2 1}}$ From the data (Table 3), it is clear that about $43 \%$ of the total raw material cost is from FTO substrate, about $34 \%$ from the HTL material (spiro-OMeTAD), and $18 \%$ from metal electrode (Au). ${ }^{120,121}$

These data suggest the need for replacement of conventional FTO substrate, HTL material and Au electrode. The efficiency of
Table 3 Cost breakdown of raw materials utilized in fabricating a PSC module of $1 \mathrm{~m}^{2}$ with $70 \%$ active area ${ }^{120,121}$

\begin{tabular}{|c|c|c|c|c|}
\hline Raw material & Qty & $\begin{array}{l}\text { Price } \\
\text { (in } \\
\text { USD) }\end{array}$ & $\begin{array}{l}\text { Contribution } \\
\text { towards } \\
\text { total } \\
\text { cost }(\%)\end{array}$ & Comments \\
\hline FTO glass & $1 \mathrm{~m}^{2}$ & 766 & 43.0500 & Processing cost of \\
\hline Ethanol & $32.84 \mathrm{ml}$ & 4.59 & & FTO is included \\
\hline DI water & $32.70 \mathrm{ml}$ & 0.002 & & \\
\hline HCL solution & $4.66 \mathrm{ml}$ & 1.8204 & & \\
\hline \multicolumn{5}{|l|}{ Blocking layer } \\
\hline TAA & $19.16 \mathrm{ml}$ & 7.339 & 0.0066 & For $100 \mathrm{~nm}$ layer \\
\hline Ethanol & $32.84 \mathrm{ml}$ & 4.59 & & and post deposition \\
\hline DI water & $32.70 \mathrm{ml}$ & 0.002 & & cleaning is included \\
\hline \multicolumn{5}{|l|}{ ETL material } \\
\hline $\mathrm{TiO}_{2}$ & $49.5 \mathrm{~g}$ & 41.12 & 0.02291 & $\begin{array}{l}\text { For } 250 \mathrm{~nm} \text { thick } \\
\text { layer }\end{array}$ \\
\hline \multicolumn{5}{|l|}{ Perovskite layer } \\
\hline $\mathrm{PbI}_{2}$ & $1.38 \mathrm{~g}$ & 4.26 & 0.003811 & For $100 \mathrm{~nm}$ thick \\
\hline DMF & $2.98 \mathrm{ml}$ & 0.5502 & & solvent $\mathrm{PbI}_{2}$ followed \\
\hline MAI & $0.143 \mathrm{~g}$ & 0.49 & & by $200 \mathrm{~nm}$ thick \\
\hline IPA & $14.29 \mathrm{ml}$ & 1.538 & & solvent MAI \\
\hline \multicolumn{5}{|l|}{ HTL material } \\
\hline Spiro-OMeTAD & $0.850 \mathrm{~g}$ & 603.65 & 33.973 & For $200 \mathrm{~nm}$ thick \\
\hline Chlorobenzene & $10.67 \mathrm{ml}$ & 5.9 & & solvent HTM layer \\
\hline \multicolumn{5}{|l|}{ Cathode } \\
\hline $\mathrm{Au}$ & $1.65 \mathrm{~g}$ & 330 & 18.392 & $\begin{array}{l}\text { For } 100 \mathrm{~nm} \\
\text { thick layer }\end{array}$ \\
\hline \multicolumn{5}{|l|}{ Encapsulation } \\
\hline $3 \mathrm{M}$ tape & & 22.32 & 0.012 & Taped on \\
\hline PET & $61.7 \mathrm{~g}$ & 0.03 & & both sides \\
\hline
\end{tabular}

the PSCs device on ITO-free analogues achieved 11\%. ${ }^{122}$ Some new and cheap HTL materials have been reported, such as NiO $(\mathrm{PCE} \sim 18.47 \%),{ }^{79}$ triazine-Th-OMeTPA (PCE $\left.\sim 12.51 \%\right),{ }^{75}$ $\mathrm{CuGaO}_{2}(\mathrm{PCE} \sim 18.51 \%),{ }^{54} \mathrm{CuSCN}(\mathrm{PCE} \sim 20.4 \%),{ }^{74} \mathrm{NiMgLiO}$ (PCE 16.2\%), ${ }^{41}$ etc. Meanwhile, the efficiency for carbon based HTM-free PSCs devices achieved 15.9\% ${ }^{81}$ Although, the PCE of spiro-OMeTAD-free PSCs device is little lower than the conventional PSCs, with small sacrifice in efficiency, low-cost and highly stable carbon based HTM-free PSCs can be fabricated.

\subsection{Environmental issues - the presence of lead}

Environmental issues are a well-recognized issue for PSCs. ${ }^{\mathbf{1 0 4 , 1 2 3}}$ Like CdTe, a toxic heavy metal exists in the PSCs devices. But, the CdTe is very chemically stable, organolead halide perovskites are not stable and upon ambient exposure they can degrade into products that are readily leached into the environment. ${ }^{104,123}$ In the life cycle assessments (LCA), the hazards of $\mathrm{Pb}$ for environmental impacts exist in all stages, which include raw material extraction, synthesis of starting products, fabrication, use and decommissioning. ${ }^{120}$ Thus, ideally PSCs should be subject to even more stringent safety standards and 
any commercial products should have clear plans for end-of-life disposal and/or recycling..$^{104,123}$

To address the concerns about lead, lead-free perovskite materials have attracted the attention of many researchers, which include tin-based perovskite materials and other perovskites materials (lead-free and tin-free perovskites, such as $\mathrm{MA}_{2} \mathrm{CuCl}_{x} \mathrm{Br}_{4-x},{ }^{124} \mathrm{CsGeI}_{3}, \mathrm{MAGeI}_{3}$, and $\mathrm{FAGeI}_{3},{ }^{125} \mathrm{~A}_{3} \mathrm{Sb}_{2} \mathrm{I}_{9}(\mathrm{~A}=$ Cs, $\mathrm{Rb}$ ), ${ }^{126} \mathrm{Cs}_{2} \mathrm{BiAgCl}_{6},{ }^{127}$ ( $N$-methylpyrrolidinium) ${ }_{3} \mathrm{Sb}_{2} \mathrm{Br}_{9},{ }^{128}$ etc.). But, compare with lead-based perovskites, the efficiencies of tin-based PSCs commonly well below $10 \%,{ }^{129,130}$ the PCE values for other perovskites have been below $1 \% .^{124-126}$

Thus, improving encapsulation technologies, it could limit the $\mathrm{Pb}$ leakage during the cell operation. Researching the leadfree perovskite materials, achieving high performance lead-free PSCs device, which could to replace the lead-based PSCs device.

\section{Conclusions}

In this article, we briefly summarized the studies on large-area PSCs in recent years. Progress has been made in manufacturing larger area cells as well as modules, which is the interesting for commercialization of the technology. Approaches for fabricating the lager-area perovskite film layer are described such as spin-coating, vapor deposition, gas-induced and blade coating etc. It is demonstrated that these processes are useful to realize more uniform perovskite layer with larger grain sized and better surface coverage, which strongly affect consequent photovoltaic performance of devices.

Going forward, PSCs will have to reduce non-radiative recombination and improve charge transport in order to achieve the highest possible $V_{\mathrm{oc}}$ values and fill factors. For the largearea PSCs device, improving the PCE, the first method is to change the chemical composition of perovskite, adjusting its band gap and increasing the charge generation. The second approach is to increase the grain size of perovskite, decreasing the cracks and pinholes, that reduces the bulk defect recombination and electric leakage, and increase $V_{\text {oc }}$. The third approach is interface modification, which reduces interface contact resistance, and reduce interface and surface recombination, and increase $J_{\mathrm{sc}}$. Meanwhile, one key issue of the largearea PSCs is the long-term poor stability. To the improving of the stability of PSCs, which requires interdisciplinary research to find new stable materials, the choice of electrodes, barrier layers, charge transport layers and encapsulation strategies. Undoubtedly, in the near future, halide perovskite materials have emerged as an attractive alternative to conventional silicon solar cells.

\section{Conflicts of interest}

The authors declare that there is no conflict of interests regarding the publication of this paper.

\section{Acknowledgements}

This project was supported by National Science Foundation of China (NSFC No. 61574009 and No. 11574014).

\section{References}

1 H. Tang, S. He and C. Peng, Nanoscale Res. Lett., 2017, 12, 410.

2 M. K. Nazeeruddin, Nature, 2016, 538, 463-464.

3 W. S. Yang, B. W. Park, E. H. Jung, N. J. Jeon, Y. C. Kim, D. U. Lee, S. S. Shin, J. Seo, E. K. Kim, J. H. Noh and S. I. Seok, Science, 2017, 356, 1376.

4 S. De Wolf, J. Holovsky, S. J. Moon, P. Loper, B. Niesen, M. Ledinsky, F. J. Haug, J. H. Yum and C. Ballif, J. Phys. Chem. Lett., 2014, 5, 1035-1039.

5 S. D. Stranks, G. E. Eperon, G. Grancini, C. Menelaou, M. J. Alcocer, T. Leijtens, L. M. Herz, A. Petrozza and H. J. Snaith, Science, 2013, 342, 341.

6 A. Kojima, K. Teshima, Y. Shirai and T. Miyasaka, J. Am. Chem. Soc., 2009, 131, 6050.

7 L. Etgar, P. Gao, Z. Xue, Q. Peng, A. K. Chandiran, B. Liu, M. K. Nazeeruddin and M. Grätzel, J. Am. Chem. Soc., 2012, 134, 17396-17399.

8 M. Liu, M. B. Johnston and H. J. Snaith, Nature, 2013, 501, 395-398.

9 H. J. Snaith, J. Phys. Chem. Lett., 2013, 4, 3623-3630.

10 Y. Ogomi, A. Morita, S. Tsukamoto, T. Saitho, N. Fujikawa, Q. Shen, T. Toyoda, K. Yoshino, S. S. Pandey, T. Ma and S. Hayase, J. Phys. Chem. Lett., 2014, 5, 1004-1011.

11 J. Yang, B. D. Siempelkamp, D. Liu and T. L. Kelly, ACS Nano, 2015, 9, 1955-1963.

12 W. Ke, G. Fang, Q. Liu, L. Xiong, P. Qin, H. Tao, J. Wang, H. Lei, B. Li, J. Wan, G. Yang and Y. Yan, J. Am. Chem. Soc., 2015, 137, 6730-6733.

13 Z. L. Tseng, C. H. Chiang and C. G. Wu, Sci. Rep., 2015, 5, 13211.

14 M. Wang, C. Shi, J. Zhang, N. Wu and C. Ying, J. Solid State Chem., 2015, 231, 20-24.

15 C. Zuo and L. Ding, J. Mater. Chem. A, 2015, 3, 9063-9066.

16 C.-Y. Chang, W.-K. Huang, Y.-C. Chang, K.-T. Lee and C.-T. Chen, J. Mater. Chem. A, 2016, 4, 640-648.

17 F. Bella, G. Griffini, J. P. Correa-Baena, G. Saracco, M. Grätzel, A. Hagfeldt, S. Turri and C. Gerbaldi, Science, 2016, 354, 203.

18 B. Abdollahi Nejand, P. Nazari, S. Gharibzadeh, V. Ahmadi and A. Moshaii, Chem. Commun., 2017, 53, 747-750.

19 K. A. Bush, A. F. Palmstrom, Z. J. Yu, M. Boccard, R. Cheacharoen, J. P. Mailoa, D. P. McMeekin, R. L. Z. Hoye, C. D. Bailie, T. Leijtens, I. M. Peters, M. C. Minichetti, N. Rolston, R. Prasanna, S. Sofia, D. Harwood, W. Ma, F. Moghadam, H. J. Snaith, T. Buonassisi, Z. C. Holman, S. F. Bent and M. D. McGehee, Nat. Energy, 2017, 2, 17009.

20 D. Dong, H. Deng, C. Hu, H. Song, K. Qiao, X. Yang, J. Zhang, F. Cai, J. Tang and H. Song, Nanoscale, 2017, 9, 1567-1574.

21 H. Deng, X. Yang, D. Dong, B. Li, D. Yang, S. Yuan, K. Qiao, Y. B. Cheng, J. Tang and H. Song, Nano Lett., 2015, 15, 79637969.

22 S. Tong, H. Wu, C. Zhang, S. Li, C. Wang, J. Shen, S. Xiao, J. He, J. Yang, J. Sun and Y. Gao, Org. Electron., 2017, 49, 347-354. 
23 X. L. Yang, X. W. Zhang, J. X. Deng, Z. M. Chu, Q. Jiang, J. H. Meng, P. Y. Wang, L. Q. Zhang, Z. G. Yin and J. B. You, Nat. Commun., 2018, 9, 570.

24 H. Wu, S. H. Xu, H. B. Shao, L. Li, Y. P. Cui and C. L. Wang, Nanoscale, 2017, 9, 16858-16863.

25 S. J. Kim, J. Byun, T. Jeon, H. M. Jin, H. R. Hong and S. O. Kim, ACS Appl. Mater. Interfaces, 2018, 10, 2490-2495.

26 W. Zou, R. Z. Li, S. T. Zhang, Y. L. Liu, N. N. Wang, Y. Cao, Y. F. Miao, M. M. Xu, Q. Guo, D. W. Di, L. Zhang, C. Yi, F. Gao, R. H. Friend, J. P. Wang and W. Huang, Nat. Commun., 2018, 9, 608.

27 H. S. Kim, C. R. Lee, J. H. Im, K. B. Lee, T. Moehl, A. Marchioro, S. J. Moon, R. Humphry-Baker, J. H. Yum, J. E. Moser, M. Grätzel and N. G. Park, Sci. Rep., 2012, 2, 591.

28 H. Zhou, Q. Chen, G. Li, S. Luo, T. B. Song, H. S. Duan, Z. Hong, J. You, Y. Liu and Y. Yang, Science, 2014, 345, 542-546.

29 W. S. Yang, J. H. Noh, N. J. Jeon, Y. C. Kim, S. Ryu, J. Seo and S. I. Seok, Science, 2015, 348, 1234.

30 O. Ergen, S. M. Gilbert, T. Pham, S. J. Turner, M. T. Z. Tan, M. A. Worsley and A. Zettl, Nat. Mater., 2017, 16, 522-525.

31 H. Tan, A. Jain, O. Voznyy, X. Lan, F. P. Garcia de Arquer, J. Z. Fan, R. Quintero-Bermudez, M. Yuan, B. Zhang, Y. Zhao, F. Fan, P. Li, L. N. Quan, Y. Zhao, Z. H. Lu, Z. Yang, S. Hoogland and E. H. Sargent, Science, 2017, 355, 722-726.

32 X. Chen, H. Cao, H. Yu, H. Zhu, H. Zhou, L. Yang and S. Yin, J. Mater. Chem. A, 2016, 4, 9124-9132.

33 L.-L. Gao, C.-X. Li, C.-J. Li and G.-J. Yang, J. Mater. Chem. A, 2017, 5, 1548-1557.

34 J. Lee, H. Kang, G. Kim, H. Back, J. Kim, S. Hong, B. Park, E. Lee and K. Lee, Adv. Mater., 2017, 29, 1606363.

35 M. Kim, G. H. Kim, K. S. Oh, Y. Jo, H. Yoon, K. H. Kim, H. Lee, J. Y. Kim and D. S. Kim, ACS Nano, 2017, 11, 6057-6064.

36 H. Chen, F. Ye, W. Tang, J. He, M. Yin, Y. Wang, F. Xie, E. Bi, X. Yang, M. Grätzel and L. Han, Nature, 2017, 550, 92-95.

37 X. Li, D. Bi, C. Yi, J. D. Décoppet, J. Luo, S. M. Zakeeruddin, A. Hagfeldt and M. Grätzel, Science, 2016, 353, 58.

38 Q. Jiang, Z. Chu, P. Wang, X. Yang, H. Liu, Y. Wang, Z. Yin, J. Wu, X. Zhang and J. You, Adv. Mater., 2017, 29, 1703852.

39 W. Qiu, T. Merckx, M. Jaysankar, C. Masse de la Huerta,

L. Rakocevic, W. Zhang, U. W. Paetzold, R. Gehlhaar, L. Froyen, J. Poortmans, D. Cheyns, H. J. Snaith and P. Heremans, Energy Environ. Sci., 2016, 9, 484-489.

40 Y. Tu, J. Wu, X. He, P. Guo, T. Wu, H. Luo, Q. Liu, Q. Wu, J. Lin, M. Huang, Z. Lan and S. Li, J. Mater. Chem. A, 2017, 5, 21161-21168.

41 W. Chen, Y. Wu, Y. Yue, J. Liu, W. Zhang, X. Yang, H. Chen, E. Bi, I. Ashraful, M. Grätzel and L. Y. Han, Science, 2015, 350, 944-948.

42 Y. Wu, X. Yang, W. Chen, Y. Yue, M. Cai, F. Xie, E. Bi, A. Islam and L. Han, Nat. Energy, 2016, 1, 16148.

43 S. Cacovich, L. Cina, F. Matteocci, G. Divitini, P. A. Midgley, A. Di Carlo and C. Ducati, Nanoscale, 2017, 9, 4700-4706.

44 Y. He, Y. Lei, X. Yang, K. Lu, S. Liu, L. Gu and Z. Zheng, Appl. Surf. Sci., 2016, 389, 540-546.
45 C.-Y. Chang, Y.-C. Chang, W.-K. Huang, W.-C. Liao, H. Wang, C. Yeh, B.-C. Tsai, Y.-C. Huang and C.-S. Tsao, J. Mater. Chem. A, 2016, 4, 7903-7913.

46 K. Yao, X. Wang, Y.-x. Xu, F. Li and L. Zhou, Chem. Mater., 2016, 28, 3131-3138.

47 S. Razza, F. Di Giacomo, F. Matteocci, L. Cinà, A. L. Palma, S. Casaluci, P. Cameron, A. D'Epifanio, S. Licoccia, A. Reale, T. M. Brown and A. Di Carlo, J. Power Sources, 2015, 277, 286-291.

48 G. Niu, X. Guo and L. Wang, J. Mater. Chem. A, 2015, 3, 8970-8980.

49 J. P. Correa-Baena, M. Saliba, T. Buonassisi, M. Grätzel, A. Abate, W. Tress and A. Hagfeldt, Science, 2017, 358, 739-744.

50 M. K. Assadi, S. Bakhoda, R. Saidur and H. Hanaei, Renewable Sustainable Energy Rev., 2017, 81, 2812-2822.

51 N.-G. Park, Mater. Today, 2015, 18, 65-72.

52 H. S. Kim, J. W. Lee, N. Yantara, P. P. Boix, S. A. Kulkarni, S. Mhaisalkar, M. Grätzel and N. G. Park, Nano Lett., 2013, 13, 2412-2417.

53 M. I. Asghar, J. Zhang, H. Wang and P. D. Lund, Renewable Sustainable Energy Rev., 2017, 77, 131-146.

54 H. Zhang, H. Wang, W. Chen and A. K. Jen, Adv. Mater., 2017, 29, 1604984.

55 M. M. Tavakoli, R. Tavakoli, Z. Nourbakhsh, A. Waleed, U. S. Virk and Z. Fan, Adv. Mater. Interfaces, 2016, 3, 1500790.

56 J. You, L. Meng, T. B. Song, T. F. Guo, Y. M. Yang, W. H. Chang, Z. Hong, H. Chen, H. Zhou, Q. Chen, Y. Liu, N. De Marco and Y. Yang, Nat. Nanotechnol., 2016, 11, 75-81.

57 Q. Jiang, L. Zhang, H. Wang, X. Yang, J. Meng, H. Liu, Z. Yin, J. Wu, X. Zhang and J. You, Nat. Energy, 2016, 2, 16177.

58 Z. Liu, J. Hu, H. Jiao, L. Li, G. Zheng, Y. Chen, Y. Huang, Q. Zhang, C. Shen, Q. Chen and H. Zhou, Adv. Mater., 2017, 29, 1606774.

59 L. Zuo, H. Guo, D. W. Dequilettes, S. Jariwala, N. D. Marco, S. Dong, R. Deblock, D. S. Ginger, B. Dunn and M. Wang, Sci. Adv., 2017, 3, e1700106.

60 J. You, Z. Hong, Y. M. Yang, Q. Chen, M. Cai, T. B. Song, C. C. Chen, S. Lu, Y. Liu and H. Zhou, ACS Nano, 2014, 8, 1674.

61 X. Bao, Y. Wang, Q. Zhu, N. Wang, D. Zhu, J. Wang, A. Yang and R. Yang, J. Power Sources, 2015, 297, 53-58.

62 H. Tsai, W. Nie, J.-C. Blancon, C. C. Stoumpos, R. Asadpour, B. Harutyunyan, A. J. Neukirch, R. Verduzco, J. J. Crochet and S. Tretiak, Nature, 2016, 536, 312.

63 J. Werner, C. H. Weng, A. Walter, L. Fesquet, J. P. Seif, S. De Wolf, B. Niesen and C. Ballif, J. Phys. Chem. Lett., 2016, 7, 161-166.

64 F. Xie, C.-C. Chen, Y. Wu, X. Li, M. Cai, X. Liu, X. Yang and L. Han, Energy Environ. Sci., 2017, 10, 1942-1949.

65 L. Yang, F. Cai, Y. Yan, J. Li, D. Liu, A. J. Pearson and T. Wang, Adv. Funct. Mater., 2017, 27, 1702613.

66 S. S. Shin, E. J. Yeom, W. S. Yang, S. Hur, M. G. Kim, J. Im, J. Seo, J. H. Noh and S. I. Seok, Science, 2017, 356, 167-171. 
67 J. Peng, T. Duong, X. Zhou, H. Shen, Y. Wu, H. K. Mulmudi, Y. Wan, D. Zhong, J. Li, T. Tsuzuki, K. J. Weber, K. R. Catchpole and T. P. White, Adv. Energy Mater., 2017, 7, 1601768.

68 T. Duong, Y. Wu, H. Shen, J. Peng, X. Fu, D. Jacobs, E.-C. Wang, T. C. Kho, K. C. Fong, M. Stocks, E. Franklin, A. Blakers, N. Zin, K. McIntosh, W. Li, Y.-B. Cheng, T. P. White, K. Weber and K. Catchpole, Adv. Energy Mater., 2017, 7, 1700228.

69 Z. Qiu, S. Yuan, H. Gong, H. Zhang, X. Qiu, T. Luo, B. Cao and H. Du, J. Am. Ceram. Soc., 2017, 100, 176-184.

70 N. Y. Nia, F. Matteocci, L. Cina and A. Di Carlo, ChemSusChem, 2017, 10, 3854-3860.

71 T. Gatti, S. Casaluci, M. Prato, M. Salerno, F. Di Stasio, A. Ansaldo, E. Menna, A. Di Carlo and F. Bonaccorso, Adv. Funct. Mater., 2016, 26, 7443-7453.

72 H. Choi, J. Jeong, H.-B. Kim, S. Kim, B. Walker, G.-H. Kim and J. Y. Kim, Nano Energy, 2014, 7, 80-85.

73 S. Ye, W. Sun, Y. Li, W. Yan, H. Peng, Z. Bian, Z. Liu and C. Huang, Nano Lett., 2015, 15, 3723-3728.

74 N. Arora, M. I. Dar, A. Hinderhofer, N. Pellet, F. Schreiber, S. M. Zakeeruddin and M. Grätzel, Science, 2017, 358, 768-771.

75 K. Do, H. Choi, K. Lim, H. Jo, J. W. Cho, M. K. Nazeeruddin and J. Ko, Chem. Commun., 2014, 50, 10971-10974.

76 Y. Xu, T. Bu, M. Li, T. Qin, C. Yin, N. Wang, R. Li, J. Zhong, H. Li, Y. Peng, J. Wang, L. Xie and W. Huang, ChemSusChem, 2017, 10, 2578-2584.

77 X. Liu, F. Kong, Z. a. Tan, T. Cheng, W. Chen, T. Yu, F. Guo, J. Chen, J. Yao and S. Dai, RSC Adv., 2016, 6, 87454-87460.

78 W. Chen, L. Xu, X. Feng, J. Jie and Z. He, Adv. Mater., 2017, 29, 1603923.

79 Y. Bai, S. Xiao, C. Hu, T. Zhang, X. Y. Meng, Q. Li, Y. L. Yang, K. S. Wong, H. N. Chen and S. H. Yang, Nano Energy, 2017, 34, 58-68.

80 J. B. Zhang, B. Xu, L. Yang, C. Q. Ruan, L. Q. Wang, P. Liu, W. Zhang, N. Vlachopoulos, L. Kloo, G. Boschloo, L. C. Sun, A. Hagfeldt and E. M. J. Johansson, Adv. Energy Mater., 2018, 8, 1701209.

81 H. Zhang, H. Wang, S. T. Williams, D. Xiong, W. Zhang, C. C. Chueh, W. Chen and A. K. Jen, Adv. Mater., 2017, 29, 1-8.

82 A. Mei, X. Li, L. Liu, Z. Ku, T. Liu, Y. Rong, M. Xu, M. Hu, J. Chen and Y. Yang, Science, 2014, 345, 295.

83 J. Chen, Y. Rong, A. Mei, Y. Xiong, T. Liu, Y. Sheng, P. Jiang, L. Hong, Y. Guan, X. Zhu, X. Hou, M. Duan, J. Zhao, X. Li and H. Han, Adv. Energy Mater., 2016, 6, 1502009.

84 X. Jiang, Y. Xiong, A. Mei, Y. Rong, Y. Hu, L. Hong, Y. Jin, Q. Liu and H. Han, J. Phys. Chem. Lett., 2016, 7, 4142-4146.

85 Z. Liu, T. Shi, Z. Tang, B. Sun and G. Liao, Nanoscale, 2016, 8, 7017-7023.

86 L. Huang, Z. Hu, J. Xu, K. Zhang, J. Zhang and Y. Zhu, Sol. Energy Mater. Sol. Cells, 2015, 141, 377-382.

87 X. Huang, Z. Hu, J. Xu, P. Wang, L. Wang, J. Zhang and Y. Zhu, Sol. Energy Mater. Sol. Cells, 2017, 164, 87-92.

88 J. Kim, J. S. Yun, Y. Cho, D. S. Lee, B. Wilkinson, A. M. Soufiani, X. Deng, J. Zheng, A. Shi, S. Lim, S. Chen,
Z. Hameiri, M. Zhang, C. F. J. Lau, S. Huang, M. A. Green and A. W. Y. Ho-Baillie, ACS Energy Lett., 2017, 2, 19781984.

89 F. Zhang, W. Shi, J. Luo, N. Pellet, C. Yi, X. Li, X. Zhao, T. J. S. Dennis, X. Li, S. Wang, Y. Xiao, S. M. Zakeeruddin, D. Bi and M. Grätzel, Adv. Mater., 2017, 29, 1606806.

90 N. Aeineh, E. M. Barea, A. Behjat, N. Sharifi and I. MoraSero, ACS Appl. Mater. Interfaces, 2017, 9, 13181-13187.

91 M. Hambsch, Q. Lin, A. Armin, P. L. Burn and P. Meredith, J. Mater. Chem. A, 2016, 4, 13830-13836.

92 Y. Zhou and N. P. Padture, ACS Energy Lett., 2017, 2, 21662176.

93 Z. Zhou, Z. Wang, Y. Zhou, S. Pang, D. Wang, H. Xu, Z. Liu, N. P. Padture and G. Cui, Angew. Chem., Int. Ed., 2015, 54, 9705-9709.

94 Q. Hu, H. Wu, J. Sun, D. Yan, Y. Gao and J. Yang, Nanoscale, 2016, 8, 5350-5357.

95 Y. Hou, X. Du, S. Scheiner, D. P. McMeekin, Z. Wang, N. Li, M. S. Killian, H. Chen, M. Richter, I. Levchuk, N. Schrenker, E. Spiecker, T. Stubhan, N. A. Luechinger, A. Hirsch, P. Schmuki, H. P. Steinruck, R. H. Fink, M. Halik, H. J. Snaith and C. J. Brabec, Science, 2017, 358, 1192-1197.

96 A. Luque and S. Hegedus, Handbook of photovoltaic science and engineering, John Wiley \& Sons, 2011.

97 W. T. Deng, X. X. Liang, P. S. Kubiak and P. J. Cameron, Adv. Energy Mater., 2018, 8, 1701544.

98 P. P. Boix, K. Nonomura, N. Mathews and S. G. Mhaisalkar, Mater. Today, 2014, 17, 16-23.

99 W.-J. Yin, J.-H. Yang, J. Kang, Y. Yan and S.-H. Wei, J. Mater. Chem. A, 2015, 3, 8926-8942.

100 G. E. Eperon and D. S. Ginger, Nat. Energy, 2016, 1, 16109.

101 X. Tong, F. Lin, J. Wu and Z. M. Wang, Adv. Sci., 2016, 3, 1500201.

102 V. Adinolfi, W. Peng, G. Walters, O. M. Bakr and E. H. Sargent, Adv. Mater., 2018, 30, 1700764.

103 M. E. Calvo, J. Mater. Chem. A, 2017, 5, 20561-20578.

104 A. B. Djurišić, F. Z. Liu, H. W. Tam, M. K. Wong, A. Ng, C. Surya, W. Chen and Z. B. He, Prog. Quantum Electron., 2017, 53, 1-37.

105 M. L. Petrus, J. Schlipf, C. Li, T. P. Gujar, N. Giesbrecht, P. Muller-Buschbaum, M. Thelakkat, T. Bein, S. Huttner and P. Docampo, Adv. Energy Mater., 2017, 7, 1700264.

106 Y. Yang and J. B. You, Nature, 2017, 544, 155.

107 M. Ye, X. Hong, F. Zhang and X. Liu, J. Mater. Chem. A, 2016, 4, 6755-6771.

108 B. Conings, J. Drijkoningen, N. Gauquelin, A. Babayigit, J. D'Haen, L. D'Olieslaeger, A. Ethirajan, J. Verbeeck, J. Manca, E. Mosconi, F. D. Angelis and H.-G. Boyen, Adv. Energy Mater., 2015, 5, 1500477.

109 B. Philippe, B.-W. Park, R. Lindblad, J. Oscarsson, S. Ahmadi, E. M. J. Johansson and H. Rensmo, Chem. Mater., 2015, 27, 1720-1731.

110 J. M. Frost, K. T. Butler, F. Brivio, C. H. Hendon, M. van Schilfgaarde and A. Walsh, Nano Lett., 2014, 14, 2584-2590.

111 H. S. Kim, J. Y. Seo and N. G. Park, ChemSusChem, 2016, 9, 2528. 
112 A. M. A. Leguy, Y. Hu, M. Campoy-Quiles, M. I. Alonso, O. J. Weber, P. Azarhoosh, M. van Schilfgaarde, M. T. Weller, T. Bein, J. Nelson, P. Docampo and P. R. F. Barnes, Chem. Mater., 2015, 27, 3397-3407.

113 T. Leijtens, G. E. Eperon, S. Pathak, A. Abate, M. M. Lee and H. J. Snaith, Nat. Commun., 2013, 4, 2885.

114 Y. Chen, Y. Sun, J. Peng, J. Tang, K. Zheng and Z. Liang, Adv. Mater., 2018, 30, 1703487.

115 H. Tsai, W. Nie, J. C. Blancon, C. C. Stoumpos, R. Asadpour, B. Harutyunyan, A. J. Neukirch, R. Verduzco, J. J. Crochet, S. Tretiak, L. Pedesseau, J. Even, M. A. Alam, G. Gupta, J. Lou, P. M. Ajayan, M. J. Bedzyk and M. G. Kanatzidis, Nature, 2016, 536, 312-316.

116 M. Saliba, T. Matsui, K. Domanski, J. Y. Seo, A. Ummadisingu, S. M. Zakeeruddin, J. P. Correabaena, W. R. Tress, A. Abate, A. Hagfeldt and M. Grätzel, Science, 2016, 354, 206.

117 A. Agresti, S. Pescetelli, L. Cinà, D. Konios, G. Kakavelakis, E. Kymakis and A. D. Carlo, Adv. Funct. Mater., 2016, 26, 2686-2694.

118 D. Bi, G. Boschloo, S. Schwarzmuller, L. Yang, E. M. Johansson and A. Hagfeldt, Nanoscale, 2013, 5, 11686-11691.

119 B. Li, Y. Zhang, L. Zhang and L. Yin, Adv. Mater., 2017, 29, 1701221.

120 J. Gong, S. B. Darling and F. Q. You, Energy Environ. Sci., 2015, 8, 1953-1968.

121 S. Maniarasu, T. B. Korukonda, V. Manjunath, E. Ramasamy, M. Ramesh and G. Veerappan, Renewable Sustainable Energy Rev., 2018, 82, 845-857.
122 T. Hu, T. Becker, N. Pourdavoud, J. Zhao, K. O. Brinkmann, R. Heiderhoff, T. Gahlmann, Z. Huang, S. Olthof, K. Meerholz, D. Tobbens, B. Cheng, Y. Chen and T. Riedl, Adv. Mater., 2017, 29, 1606656.

123 A. Babayigit, A. Ethirajan, M. Muller and B. Conings, Nat. Mater., 2016, 15, 247-251.

124 D. Cortecchia, H. A. Dewi, J. Yin, A. Bruno, S. Chen, T. Baikie, P. P. Boix, M. Grätzel, S. Mhaisalkar, C. Soci and N. Mathews, Inorg. Chem., 2016, 55, 1044-1052.

125 T. Krishnamoorthy, H. Ding, C. Yan, W. L. Leong, T. Baikie, Z. Y. Zhang, M. Sherburne, S. Li, M. Asta, N. Mathews and S. G. Mhaisalkar, J. Mater. Chem. A, 2015, 3, 23829-23832.

126 P. C. Harikesh, H. K. Mulmudi, B. Ghosh, T. W. Goh, Y. T. Teng, K. Thirumal, M. Lockrey, K. Weber, T. M. Koh, S. Z. Li, S. Mhaisalkar and N. Mathews, Chem. Mater., 2016, 28, 7496-7504.

127 G. Volonakis, M. R. Filip, A. A. Haghighirad, N. Sakai, B. Wenger, H. J. Snaith and F. Giustino, J. Phys. Chem. Lett., 2016, 7, 1254-1259.

128 Z. H. Sun, A. R. Zeb, S. J. Liu, C. M. Ji, T. Khan, L. Li, M. C. Hong and J. H. Luo, Angew. Chem., Int. Ed., 2016, 55, 11854-11858.

129 S. J. Lee, S. S. Shin, Y. C. Kim, D. Kim, T. K. Ahn, J. H. Noh, J. Seo and S. I. Seok, J. Am. Chem. Soc., 2016, 138, 39743977.

130 W. Q. Liao, D. W. Zhao, Y. Yu, C. R. Grice, C. L. Wang, A. J. Cimaroli, P. Schulz, W. W. Meng, K. Zhu, R. G. Xiong and Y. F. Yan, Adv. Mater., 2016, 28, 9333. 